\title{
EL PARLAMENTARIO INDIVIDUAL EN UN PARLAMENTO DE GRUPOS: LA PARTICIPACIÓN EN LA FUNCIÓN LEGISLATIVA
}

\author{
PIEDAD GARCÍA-ESCUDERO MÁRQUEZ \\ Catedrática de Derecho Constitucional \\ Universidad Complutense de Madrid \\ Letrada de las Cortes Generales
}

SUMARIO.

I. Introducción.

II. Normativa y jurisprudencia constitucional.

III. Facultades reglamentarias de parlamentarios y grupos.

IV Parlamentarios y grupos en el procedimiento legislativo.

V. Conclusión

\section{INTRODUCCIÓN}

A) Objeto de estudio

El comienzo de cualquier trabajo de investigación se asemeja a ponerse en camino sin una idea muy precisa del destino del viaje, ni tampoco del itinerario. Sin embargo, a medida que avanzamos, van apareciendo cruces de carreteras en las que es preciso descartar algunas de las opciones (temas de estudio igualmente apetecibles, por otra parte) ante el temor de no poder culminar la tarea y alcanzar el objetivo. Es como si se fuera despojando a un árbol de las ramas que se bifurcan para mantener recto el rumbo que lleva a la cumbre.

Así ha ocurrido también en este caso. Teniendo más claro el punto de destino (la actual situación competencial o las funciones del parlamentario individual en un Parlamento de grupos), no era fácil comenzar sin quedarse empantanado en las atractivas cuestiones que nos plantean en el camino la teoría de la representación política, el mandato imperativo y el mandato de partido, la naturaleza jurídica de los grupos parlamentarios, el artículo 23 de la Constitución y el estatuto de los parlamentarios. 
Todas estas cuestiones han tenido que ser dejadas a un lado, apenas apuntadas o como ignoradas, para llegar a examinar cuáles son las funciones parlamentarias (las funciones constitucionales de las Cámaras que integran las Cortes Generales) que en el momento actual ejerce el parlamentario individual, y cuáles los grupos parlamentarios; mostrar, en su caso, la contradicción o distancia que existe o separa la concepción constitucional de unos y otros y su ámbito de actuación en la realidad; y posicionarnos ante la situación existente.

No constituyen, pues, el objeto de estudio los grupos parlamentarios, sobre los que existe en nuestro país cierto número de monografías ${ }^{1}$. Se trata más bien, cambiando la perspectiva, de examinar la concepción del parlamentario individual ${ }^{2}$ (supuesto autor, todavía titular del mandato representativo, del ejercicio de las funciones constitucionales de las Cámaras) que se obtiene de la Constitución y la jurisprudencia constitucional y compararla con la normativa contenida en los Reglamentos parlamentarios y con su aplicación práctica, para comprobar cuál es el ámbito de actuación que conserva aquél y cuál ha sido «usurpado» por los grupos parlamentarios, protagonistas del juego político y de la inmensa mayoría de las iniciativas e intervenciones en el seno de las Cámaras.

Este es el modesto y reducido propósito de este trabajo. Téngase, pues, en cuenta, que la introducción teórica al mismo no pretende ser sino tal preámbulo al tema y que tanto los grupos parlamentarios como los parlamentarios individuales se examinan exclusivamente desde el prisma que nos interesa: las funciones que ejercen ambos en el esquema de funcionamiento de la Cámara.

La realidad política aporta la justificación necesaria para abordar el estudio, aunque puedan existir otros anteriores, ${ }^{3}$ los cuales — por otra parte- suelen ser también parciales, referidos a un solo sector de la actividad parlamentaria ${ }^{4}$. En efecto, aquella revela

1 N. PÉREZ-SERRANO JÁUREGUI, Los grupos parlamentarios, Tecnos, Madrid, 1989; A. SAIZ ARNÁIZ, Los grupos parlamentarios, Congreso de los Diputados, Madrid, 1989; J.Ma. MORALES ARROYO, Los grupos parlamentarios en las Cortes Generales, CEC, Madrid, 1990; J.L. GARCÍA GUERRERO, Democracia representativa de partidos y grupos parlamentarios, Congreso de los Diputados, Madrid, 1996. Pueden verse también los números monográficos de Corts. Anuario de Derecho Parlamentario, no 10, 2001, y Asamblea, nº especial monográfico, 2007.

2 Se ha mantenido la expresión parlamentario individual por su fuerza descriptiva, pese a los reparos que le formula J. GARCÍA ROCA ( «El control del Gobierno desde la perspectiva individual del parlamentario [y a la luz del artículo 23.2 de la Constitución]», en Problemas actuales del control parlamentario. VI Jornadas de Derecho parlamentario, Congreso de los Diputados, Madrid, 1997, pág. 228, nota 2) por su carácter innecesariamente tautológico, al no poder existir otros parlamentarios que los individuales, siendo admisible, en cambio, la diferenciación entre el representante individual y el colectivo (el partido).

3 H. GÓMEZ DE LAS ROCES, «Las facultades parlamentarias de ejercicio individual», en Las Cortes Generales, Instituto de Estudios Fiscales, Madrid, 1987, págs. 1283-1297; F. SANTAOLALLA LÓPEZ, «Partido político, grupo parlamentario y diputado», en Derecho de partidos, J.J. GONZÁLEZ ENCINAR, coord., Espasa Calpe, Madrid, 1992, págs. 93-118; más recientemente, J. TUDELA ARANDA, «La posición del Diputado en el Parlamento español desde un estudio de los reglamentos internos de los Grupos Parlamentarios, Asamblea $\mathrm{n}^{\circ} 20,2009$, págs. 157-197, y C. PAUNER CHULVI, «El estatuto de los parlamentarios en un contexto multinivel: las relaciones entre parlamentarios, grupos y partidos», RDP, n 78, 2010, págs. 219-256.

4 J. GARCÍA ROCA, «El control del Gobierno desde la perspectiva individual del parlamentario ty a la luz del artículo 23.2 de la Constitución]», cit., págs. 225-277; A. CIDONCHA MARTÍN, «El control del Gobierno desde la perspectiva del parlamentario individual», en El Gobierno. Problemas constitucionales, M. ARAGÓN REYES y A.J. GÓMEZ MONTORO, Coords., CEPC, Madrid, 2005, págs. 339-406; C. G. ORTEGA SANTIAGO, «Los parlamentarios y los grupos como sujetos del control parlamentario en el procedimiento legislativo», en VI Jornadas de Derecho Parlamentario. Problemas actuales del control parlamentario, Congreso de los Diputados, Madrid, 1997, págs. 739-770. 
la evolución experimentada hasta la práctica desaparición de la relevancia real del parlamentario en la vida de las Cámaras, esto es, en el cumplimiento de las funciones constitucionales de las mismas. Como apuntara tempranamente el profesor Ramírez, en relación con los grupos parlamentarios tenemos necesariamente que movernos en un mundo en el que la imprecisión es muy alta y, desde luego, en el que un análisis meramente formal pocas luces arrojará por sí solo al problema 5 .

En una obra anterior ${ }^{6}$ he utilizado la gráfica imagen de la cuadratura del círculo para describir la dificultad de alcanzar un equilibrio entre el inevitable y necesario protagonismo de los grupos y la participación individual de los miembros de las Cámaras ${ }^{7}$. No obstante, en esta dirección deberían ir orientados nuestros esfuerzos y propuestas, como se verá más adelante. En palabras de Pérez Serrano, el mandato imperativo resulta inconciliable con el Parlamento moderno y con la complejidad de la vida; pero no menos odioso puede resultar el sometimiento al partido, que convierte al parlamentario en un número, le priva de personalidad, le induce a votar contra su conciencia y a la postre suprime el postulado constitucional de que los diputados, una vez elegidos, representan a toda la Nación.

\section{B) Probibición del mandato imperativo y crisis del mandato representativo}

En la evolución que ha experimentado el mandato parlamentario, la Revolución Francesa marca el paso del mandato imperativo al mandato representativo. Hoy día, sin embargo, se habla de mandato de partido cuando quiere aludirse al efecto que produce en el Parlamento la partitocracia que se aprecia en el Estado en general. La grupocracia sería el reflejo de aquella en el ámbito parlamentario; el Parlamento, dice García Pelayo, se ha transformado primordialmente en una Cámara de partidos y sólo por mediación y mediatización en una Cámara de diputados y senadores. Frente a esta tendencia politológica, la presencia en los textos constitucionales de la prohibición del mandato imperativo cumple, cuando menos, la función de garantizar jurídicamente la libertad de juicio y de voto del representante.

5 M. RAMÍREZ, «Teoría y práctica del grupo parlamentario», REP nº11, 1979, pág. 5. Nacidos en la práctica parlamentaria, reconocidos tardíamente y con resistencia por Constituciones o Reglamentos, los grupos han dado vida a su mundo de funciones dentro del Parlamento y han ido creando sus propias pautas de actuación que van mucho más allá de lo expresamente legislado sobre ellos. El análisis de la práctica parlamentaria se impone para intentar sintetizar cuáles sean esas funciones. El de los textos jurídicos para delimitar el alcance de las mismas.

6 P. GARCÍA-ESCUDERO MÁRQUEZ, El procedimiento legislativo ordinario en las Cortes Generales, CEPC, Madrid, 2006, pág. 675.

7 En el mismo sentido, F. SANTAOLALLA LÓPEZ, «Partido político, grupo parlamentario y diputado», cit., pág. 99, afirma que la buena salud de un sistema democrático pasa por la presencia de los tres ejes partido político, grupo parlamentario y diputados, lo que supone una especie de equilibrio más o menos estable, logrado precisamente por la fuerza contrapuesta que significa cada uno de ellos. Aunque no se alcance el óptimo equilibrio perfecto, que exista una primacía de uno de los tres factores no debe significar una anulación de los restantes, pues ello supondría lesionar a dos componentes fundamentales de la moderna democracia y de esta forma al propio sistema en su conjunto. Por eso se reclama del Derecho una postura que haga posible la función política de los tres factores. 
El paso del mandato imperativo al representativo ha sido suficientemente expuesto en nuestro país, ${ }^{8}$ llegando a la conclusión de que se ha producido una crisis también en el último por la irrupción de los partidos en todos los ámbitos, en el derecho y en la realidad política. Será lo que Garrorena ${ }^{9}$ califica acertadamente de primado del principio democrático, entendido por el Tribunal Constitucional como deber general de fidelidad a los propios electores, modificador en algunos casos de la comprensión clásica del mandato imperativo.

Para algunos autores, no violaría la prohibición constitucional del mandato imperativo ni siquiera la pérdida del escaño causada por el abandono voluntario del partido en que se fue elegido (el propio Garrorena, ${ }^{10}$ De Esteban ${ }^{11}$ ), distinguiendo así el transfuguismo de la expulsión del partido, distinción que no hizo el Tribunal Constitucional en las sentencias de $1983,{ }^{12}$ que por otra parte fundamentan su argumentación sobre el artículo 23 de la Constitución y no sobre el 67.2.

La doctrina ha apuntado la posible existencia de contradicciones en la Constitución en cuanto a la concepción del mandato que acoge, dado que distintos preceptos se alinean con el mandato representativo (señaladamente el apartado 2 del artículo 67, que prohibe el mandato imperativo, pero también el artículo 79.3, que declara el voto personal e indelegable), frente a otros $(23,68.3)$ que parecen introducir elementos del mandato de partido, partiendo de la consideración de los partidos contenida en el artículo 6 como instrumento fundamental para la participación política ${ }^{13}$.

En la doctrina del Tribunal Constitucional en relación con el mandato de los representantes, se ha querido percibir una evolución ${ }^{14}$ que iría desde las primeras sentencias (STC 5/1983 y 10/1983) que declararon la inconstitucionalidad del artículo 11.7 de la Ley de Elecciones Locales por privar del escaño al representante que dejara de pertenecer al partido que lo presentó a las elecciones, hasta otros fallos posteriores que parecen reconocer elementos del llamado mandato ideológico o mandato de partido, como son la representación proporcional (STC 40/1981), la relevancia jurídica de la adscripción política de los representantes que dota de derechos a la minoría (STC 32/1985), la recepción de los votos en las elecciones no por los candidatos singularmente considerados sino por las listas presentadas por los partidos (STC75/1985) o la fidelidad de los re-

8 Por todos, P. DE VEGA, «Significado constitucional de la representación política», REP n 44, 1985 , págs. 25 y ss., y A. TORRES DEL MORAL, «Democracia y representación en los orígenes del Estado constitucional», REP, n 203,1975 , págs. 145 y ss.

9 A GARRORENA MORALES, Representación política, elecciones generales y procesos de confianza en la España actual, IEE, Madrid, 1994, págs. 35 y ss.

10 A. GARRORENA MORALES, «Mandato parlamentario», en Enciclopedia Jurídica, Civitas, Madrid, 1995 , pág. 4168.

11 J. DE ESTEBAN, «El fenómeno español del transfuguismo político y la jurisprudencia constitucional», REP n ${ }^{\circ} 70,1990$, págs. 25 y ss.

12 Con la discrepancia de un sector de la doctrina, como F. J. BASTIDA ( Derecho de participación a través de representantes y función constitucional de los partidos políticos», REDC nº 21, 1987, págs. 199 y ss) y R. BLANCO VALDÉS (Los partidos políticos, Tecnos, Madrid, 1990, pág. 154)

13 Por todos, F. CAAMAÑO DOMÍNGUEZ, El mandato parlamentario, Congreso de los Diputados, Madrid, 1991, págs. 64 y ss.

14 Una contradicción, para J. De Esteban, «El fenómeno español del transfuguismo político y la jurisprudencia constitucional», cit., pág. 25. 
presentantes «a los compromisos políticos especificados en su programa» (STC $119 / 1990)^{15}$.

En todo caso, es claro que existe una confrontación entre la realidad jurídica y la realidad política, entre la prohibición constitucional del mandato imperativo y la dependencia fáctica de los representantes respecto de los partidos a que pertenecen ${ }^{16}$, siendo una de las primeras manifestaciones de esa confrontación el cuestionarse sobre la titularidad de los escaños en caso de conflicto entre el representante y el partido.

Todo ello demuestra la necesidad de la superación de una de las grandes ficciones sobre las que se sustenta el Derecho público. No superada en nuestro país en el ámbito constitucional (a diferencia de la Constitución portuguesa de $1976{ }^{17}$ ) ni en el legislativo $^{18}$, como tampoco en la doctrina del Tribunal Constitucional, el intento de avance en la llamada lucha contra el transfuguismo (que Jiménez de Parga califica de cáncer de la democracia) se desarrolla en dos frentes distintos: en el plano de la realidad política, mediante los pactos antitransfuguismo, primero en el ámbito local y luego a nivel general; en el plano normativo, aun manteniendo la libertad para el cambio de grupo parlamentario (probablemente por considerarla consecuencia inexcusable de la prohibición constitucional del mandato imperativo), introduciendo en los Reglamentos parlamentarios (por el momento, autonómicos —así, los de las Asambleas de las Comunidades Autónomas de Andalucía, Canarias, Cantabria, Castilla-La Mancha, Castilla y León, Cataluña, Comunidad Valenciana, Extremadura, La Rioja, Madrid y Murcia ${ }^{19}$ —, pero también en algún borrador de reforma del Reglamento del Congreso de los Diputados) la distinción entre los diputados originariamente incluidos en el Grupo Mixto, por carecer la formación política a la que pertenecen del número suficiente de miembros para formar grupo propio, y los diputados no adscritos, procedentes del abandono de otros grupos ${ }^{20}$, cuyos derechos se restringen al mínimo ${ }^{21}$.

15 Puede verse sobre esta cuestión G. ARRUEGO RODRÍGUEZ, Representación política y derecho fundamental, CEPC-Fundación Manuel Giménez Abad, Madrid, 2005, págs. 166 y ss.

16 «Las dependencias cruzadas del diputado» titula R. E. CHARLIER su prólogo a la obra de J. C. MASCLET Le rôle du député et ses attaches institutionnelles sous la Ve République (LGDJ, París, 1979, págs. I y ss), comenzando con la reflexión de si hay o no contradicción entre la función primordial que ha de cumplir el diputado y las vinculaciones que padece.

17 La cual, a la vez que prohíbe el mandato imperativo, impone la pérdida del mandato a los diputados que se inscriben en un partido distinto de aquel por el que fueron elegidos.

18 J. DE ESTEBAN propone la reforma de la LOREG para privar del escaño a quienes abandonen voluntariamente el partido por el que resultaron elegidos («El fenómeno español del transfuguismo político y la jurisprudencia constitucional», cit., pág. 31). En contra, F. SANTAOLALLA LÓPEZ («Partido político, grupo parlamentario y diputado», cit., pág. 114), quien prefiere insistir en los efectos favorables que un sistema de distritos uninominales o de voto preferencial tendría sobre el sentido de la responsabilidad del representante (pág. 116).

19 Aunque no recoja las reformas más recientes, puede consultarse sobre esta cuestión A. J. TRUJILLO PÉREZ y Ma NAVAS SÁNCHEZ, «Normativa sobre el transfuguismo en los reglamentos parlamentarios autonómicos, Corts. Anuario de Derecho Parlamentario, no 14, 2003.

20 La causa por la que se produce la salida del grupo parlamentario inicial engloba el abandono voluntario y la expulsión en prácticamente todos los Reglamentos citados, a veces formulada en términos más amplios («baja» en Andalucía, «separación del grupo» en La Rioja).

21 Puede verse a este respecto E. Soriano Hernández, El estatuto de los parlamentarios de las Comunidades Autónomas, Senado, Madrid, 2001, págs. 105 y ss. 


\section{C) Reflejo en el parlamento: partidos, grupos parlamentarios, diputados}

La crisis del mandato representativo y la interferencia de los partidos políticos ha afectado, obviamente, no solamente al momento electoral o a la titularidad de los escaños, sino también al Parlamento en su conjunto, a la organización y desarrollo de la vida parlamentaria.

Duverger $^{22}$ describía hace años las situaciones posibles en la relación entre partidos y grupos parlamentarios, que mostrarían tres fases sucesivas: la de dominio de los parlamentarios sobre el partido; la de rivalidad entre dirigentes de partido y parlamentarios y, finalmente, la de dominio del partido sobre los parlamentarios, reforzado por la identificación de los dirigentes del partido con los del grupo, con lo que el grupo parlamentario — como afirma Colliard ${ }^{23}$ — puede ser considerado como la expresión parlamentaria de un partido político, y el diputado ve reducida su función, en la expresión de Leibholz, ${ }^{24}$ a la de delegado del partido.

Son sobradamente conocidas las circunstancias que llevan a este resultado: los partidos políticos confeccionan las listas electorales, seleccionan a los candidatos que incluyen en las mismas, protagonizan (y costean) las campañas. Todo ello determina una vinculación del parlamentario al partido que condiciona su actuación posterior como supuesto representante de la voluntad popular ${ }^{25}$. Se presume que la disciplina interna en el seno del grupo parlamentario (de los distintos grupos del partido en los diversos órganos representativos) encuentra su contrapeso en la democracia interna del partido, la cual, como sabemos, es una falacia expresada en la ley de hierro de Michels.

No merece mayor comentario el aspecto jurídico de la democracia interna de los partidos, exigida por el artículo 6 de la Constitución y someramente (y con escasa eficacia) regulada primero por el artículo $4^{\circ}$ de la Ley 54/1978 y, en términos prácticamente idénticos, por el artículo 7 de la vigente Ley Orgánica 6/2002 ${ }^{26}$. Y es un hecho que los reglamentos internos de los partidos someten la posición política de los grupos parlamentarios y de sus miembros a las decisiones de los órganos directivos de aquéllos. El grupo parlamentario actuará como correa de transmisión de las directrices del partido a los parlamentarios. Y en nada cambia la situación que sean los plenarios de los grupos los que adopten formalmente las decisiones relevantes — previamente adoptadas por los órganos rectores del partido_ que se materializarán en la expresión de la voluntad de sus miembros.

22 M. DUVERGER, Los partidos políticos, FCE, México, 1957, págs. 211 y ss.

23 J.C. COLLIARD, Regímenes políticos contemporáneos, Blume, Barcelona, 1981, pág. 254.

24 G. LEIBHOLZ, Problemas fundamentales de la democracia moderna, IEP, Madrid, 1971, págs. 26-27.

25 En palabras de S. TOSI (Derecho parlamentario, trad. esp., Porrúa, México, 1996, pág. 118), la sujeción política de los candidatos hacia el partido (al que compete la potestad de presentar las listas) se traduce luego en la sujeción política de los elegidos hacia el partido mismo; así, la constitución de los grupos en las Cámaras se convierte en el instrumento de control habitual de los miembros del Parlamento por parte de las centrales extraparlamentarias de partido.

26 F. SANTAOLALLA LÓPEZ («Partido político, grupo parlamentario y diputado», cit., pág. 106) opina que la parquedad en la regulación de la vida interna de los partidos no puede achacarse a la indolencia del legislador o a su actitud contemporizadora con los fenómenos de poder internos a los partidos, sino a los límites que impone, además de la Constitución y, más particularmente, el derecho de libre asociación, la propia dificultad de esta materia para su tratamiento jurídico. Por eso piensa que tenemos que resignarnos a que la democracia interna de los partidos sea una democracia deficiente. 
Por otra parte, la doctrina del Tribunal Constitucional sobre la titularidad del escaño aparentemente protege la libertad del parlamentario frente a su partido y le permite defenderse de posibles coacciones por parte del mismo. Veremos cuando entremos en el desarrollo de sus funciones como ésta es otra falacia. No importa considerar que el parlamentario está protegido en caso de conflicto con su partido, porque la dinámica de la relación muestra que ese conflicto no se da, y que cuando se da no se trasluce al exterior (en forma de ruptura de la disciplina o cambio de grupo parlamentario) más que en un número tan mínimo de ocasiones que puede considerarse insignificante. La tónica es la subordinación absoluta del parlamentario al partido, la disolución de su individualidad en el seno del grupo parlamentario (en particular en los grupos grandes, correspondientes a los dos grandes partidos Socialista y Popular) y la ausencia de una línea propia de ejercicio de su función parlamentaria, legislativa en particular. ¿No es acaso sintomático que no haya habido en nuestra historia constitucional una sola sentencia en amparo de un parlamentario, impedido en el ejercicio de sus funciones representativas, no por los órganos rectores de las Cámaras, sino por su propio grupo parlamentario, ${ }^{27}$ con la salvedad de los casos relacionados con la pérdida del escaño? En definitiva, como señala De Vega, el mandato representativo del diputado protegido constitucionalmente se ha convertido de facto en un mandato imperativo condicionado por las órdenes del partido a que pertenezca, con lo que se genera una prevalencia de la realidad política sobre la realidad jurídica que entraña una mutación constitucional ${ }^{28}$.

Y éste sería el aspecto preocupante de la cuestión, la tendencia sobre la que habría que reflexionar para plantearse si es correcta por ser coherente con el signo de los tiempos, o si cabe proponerse un intento de su rectificación por vía jurídica (reforma de los Reglamentos parlamentarios) y política (voluntad de los partidos políticos y grupos parlamentarios de dejar o incluso fomentar una esfera de acción a sus miembros). Se trataría de recordar que, aunque en el seno del Parlamento los grupos se hayan convertido en los principales titulares de la representación política, en detrimento de los representantes individuales, porque el ordenamiento jurídico les atribuye las principales iniciativas y facultades parlamentarias, el parlamentario es portador de una representación (una porción de representación, según Ortega Santiago) propia

27 El recurso de amparo tendría que dirigirse contra un acto de un órgano de la Cámara, normalmente la Mesa, que no hubiera amparado al parlamentario en el ejercicio de sus funciones. Un caso de interés, aunque no encaja exactamente en el supuesto que se señala en el texto, es el contemplado en la reciente sentencia 57/2011, de 3 de mayo, cuyo origen es el siguiente: en la VIII legislatura, el diputado F. Garrido Peña presentó cierto número de solicitudes de informe al amparo del artículo 7 del Reglamento, que fueron inadmitidas por la Mesa del Congreso por no ir acompañadas de la firma del portavoz de su grupo. El diputado solicitó la reconsideración del acuerdo, alegando que el requisito reglamentario de «previo conocimiento» se había cumplido suficientemente con el envío previo por fax al grupo de la solicitud de informe, cuyo acuse de recibo adjuntaba. La Mesa, en su reunión de 29 de mayo de 2007, se reiteró en su acuerdo inicial, amparándose en el criterio reiterado de constatación del requisito de previo conocimiento mediante la firma del portavoz, exigencia que «no implica la autorización o coautoría de la iniciativa por parte del grupo parlamentario, sino la forma fiable de constatar el previo conocimiento reglamentariamente exigido». El diputado recurrió en amparo (recurso $\mathrm{n}^{\circ} 345 / 2008$ A) un acuerdo similar de 30 de octubre de 2007, respecto de una solicitud de informe a la Confederación Hidrográfica del Guadalquivir, alegando lesión de los derechos fundamentales reconocidos en el artículo 23 CE apartados 1 y 2, por exceso en la función de calificación de la Mesa. A la doctrina sentada en la sentencia del Tribunal Constitucional se alude más adelante, en el apartado III, pág. 216 y ss.

28 P. DE VEGA, «Significado constitucional de la representación política», cit., pág. 41. 
y autónoma conectada con la mediación de la participación política de los ciudadanos, derivada del artículo 23 de la Constitución (y constitucionalmente garantizada por la titularidad de un derecho de voto personal e indelegable y la consiguiente prohibición de que su voto se encuentre jurídicamente vinculado a la disciplina de partido) y en consecuencia ha de disponer de facultades que le permitan instrumentar esta participación, no pudiendo los grupos monopolizar la concreción de la voluntad popular en las Cámaras legislativas ${ }^{29}$.

Serían ahora nuevamente de aplicación las palabras de Burke en su célebre discurso a los electores de Bristol: «Si el gobierno y la legislación son cuestiones de juicio y de razón..., ¿qué clase de razón es aquella en la que la determinación precede a la discusión, en donde un grupo de hombres delibera y otro decide?... Las instrucciones imperativas, los mandatos que el diputado está obligado ciega e implícitamente a obedecer, votar y defender, aunque sean contrarias a las convicciones más claras de su juicio y su conciencia, son cosas totalmente desconocidas en las leyes del país y surgen de una interpretación fundamentalmente equivocada de todo el orden y tenor de nuestra constitución $»^{30}$.

\section{NORMATIVA Y JURISPRUDENCIA CONSTITUCIONAL}

\section{A) Normativa constitucional}

Afirma Manzella que, en cuanto a los diputados considerados individualmente, las normas constitucionales y reglamentarias ofrecen una imagen quizá excesivamente reductiva de su papel, teniendo la impresión de que la Constitución se ha preocupado por llevar hasta sus últimas consecuencias la lógica de la organización por grupos que, aun siendo un elemento imprescindible en todo Parlamento moderno, constituye también el elemento más problemático, habida cuenta de que a él se conectan cuestiones fundamentales de vitalidad, representatividad y renovación de las asambleas ${ }^{31}$. Sin embargo, en el desarrollo posterior de esta afirmación, se refiere exclusivamente a normas de los Reglamentos de las Cámaras, para concluir en un cierto exceso de celo de las normas reglamentarias-constitucionales «cuando se reduce el espacio vital, de iniciativa e inventiva, eventualmente heterodoxa, de cada uno de los parlamentarios».

En efecto, no es la Constitución la que otorga un papel primordial a los grupos en el seno de las Cortes Generales. Es sabido que en ella aparecen citados dos veces: la primera con ese nombre (grupos parlamentarios), al hablar de la composición de la Diputación Permanente (art. 78); y también en el artículo 99.1 (consultas del Rey para proponer candidato a Presidente del Gobierno), aunque aquí se utilice la expresión «representantes designados por los grupos políticos con representación parlamentaria», concepto que, desde un punto de vista formal, al menos, no puede identificarse con el de grupos

29 C. ORTEGA, El mandato representativo de los diputados y senadores, Congreso de los Diputados, Madrid, 2005 , págs. 58 y ss.

30 Trad. Vicente Herrero, FCE, México, 1984. Véase también C. J. FRIEDRICH, Gobierno constitucional y democracia, vol. II, IEP, Madrid, 1975, pág. 25.

31 A. MANZELLA, «Las Cortes en el sistema constitucional español», en La Constitución española de 1978. Estudio sistemático, dirigido por A. PREDIERI y E. GARCÍA DE ENTERRÍA, Madrid, 1980, pág. 468. 
parlamentarios $^{32}$. Y de hecho las consultas del Rey son más amplias, pues afectan a todos los partidos políticos con representación en el Congreso de los Diputados, incluso a los que no alcanzan a tener grupo propio e integran el Grupo Mixto ${ }^{33}$ y ha de entenderse que habrán de alcanzar a todas las formaciones políticas representadas: partidos y federaciones, coaliciones o agrupaciones de electores, entidades facultadas por el artículo 44 de la Ley Orgánica del Régimen Electoral General para presentar candidaturas.

Más allá de estas referencias expresas, García Guerrero analiza el artículo 78 de la Constitución junto a sus conexiones con los artículos 1.1 y 6, con el artículo 75 - que otorga al Pleno la posibilidad de realizar delegaciones legislativas en las comisiones- y con los artículos 68.3 y 152.1, que constitucionalizan un sistema electoral proporcional para el Congreso de los Diputados y ciertas asambleas autonómicas, llegando de esta interpretación sistemática a la conclusión de que el legislador está limitado por la Constitución en cuanto a que en todos los órganos políticos de las Cortes exista un mínimo de dos grupos parlamentarios en representación de sus partidos políticos y que siempre que se produzca una delegación de competencias del Pleno hacia otros órganos, debe procurarse la representación proporcional en éstos de los diversos grupos parlamentarios ${ }^{34}$.

Saiz Arnáiz, en cambio, afirma que la constitucionalización del grupo parlamentario significa sólo su relevancia a efectos de la composición de la Diputación Permanente y que cada diputado debe poder inscribirse en un grupo parlamentario para tener opción a formar parte de la Diputación Permanente en representación del mismo, debiendo ser la presencia de los grupos en este órgano parlamentario proporcional a su importancia numérica (tutela de las minorías y garantía del mantenimiento de la mayoría). No obstante, entiende que ex Constitutione nada impediría que los Reglamentos de las Cámaras se limitasen a reconocer la existencia de los grupos parlamentarios a los únicos efectos de establecer su presencia en la Diputación Permanente, pero no podrían ser prohibidos, desde el momento que la Constitución, aunque sea con efectos limitados, los reconoce ${ }^{35}$.

Cualquiera que sea la interpretación del artículo 78 que se adopte, extensiva o limitativa, es claro que no existen otras referencias a los grupos parlamentarios en la Constitución que las dos señaladas, que afectan en el caso examinado a la composición de un órgano interno, sin que ninguna de las dos contenga menciones al ejercicio de funciones de las Cámaras.

No ocurre así con los miembros de las Cámaras, que aparecen profusamente en el Título III de la Constitución. Aparte de la referencia genérica en el artículo 23 a los representantes libremente elegidos en elecciones periódicas, y aun cuando las funciones y

32 El anteproyecto de Constitución preveía que las consultas del Rey se hicieran a los dos Presidentes de las Cámaras y los portavoces designados por los grupos parlamentarios. F. SANTAOLALLA («Comentario al artículo 99», en Comentarios a la Constitución, dirigidos por F. GARRIDO FALLA, $3^{\text {a }}$ ed., Civitas, Madrid, 2001, pág. 1549) indica que fue la consideración de que no estuviesen constituidos los grupos parlamentarios en el momento de elaborar la candidatura la que determinó la modificación en la redacción.

33 Con alguna excepción, como recuerda A. BAR CENDÓN, «Artículo 99: Nombramiento del Presidente del Gobierno», en Comentarios a la Constitución española de 1978, dirigidos por O. ÁLZAGA, tomo VIII, Edersa, Madrid, 1998, págs. 267-268.

34 J.L. GARCÍA GUERRERO, Democracia representativa de partidos y grupos parlamentarios, cit., págs. 172 y ss.

35 A. SAIZ ARNÁIZ, Los grupos parlamentarios, cit., págs. 92-93. 
las prerrogativas de las Cámaras son atribuidas por el artículo 66 a las Cortes Generales, los preceptos que se enumeran a continuación aluden a los diputados y senadores: - el artículo 67.1 prohíbe la acumulación de actas al Congreso de los Diputados y al Senado, o de diputado al Congreso y a una Asamblea de Comunidad Autónoma; - el artículo 67.2 declara que los miembros de las Cortes Generales no estarán ligados por mandato imperativo alguno, prohibición de la que ya nos hemos ocupado; - el artículo 67.3 se refiere a las reuniones de parlamentarios sin convocatoria reglamentaria; — el artículo 68 concreta el número de diputados que componen el Congreso, su distribución en circunscripciones, su elección atendiendo a criterios de representación proporcional y la duración del mandato; - el artículo 69 determina asimismo el número y elección de los senadores, así como la duración de su mandato; - el artículo 70 establece (y remite a la ley electoral) las causas mínimas de ineligibilidad e incompatibilidad de diputados y senadores y somete al control judicial la validez de las actas de diputados y senadores; — el artículo 71 contempla los privilegios o garantías de los parlamentarios (inviolabilidad, inmunidad y fuero) y el derecho a una asignación.

Dejando de lado el aspecto electoral, a los efectos de nuestro estudio nos interesa centrarnos en la presencia del parlamentario individual (una vez electo y miembro de una Cámara) y de los grupos parlamentarios en la Constitución. Cualesquiera que sean las aproximaciones que se hagan a los preceptos constitucionales, parece indudable que, como dice Fernández Segado, ${ }^{36}$ las personas electas no pueden quedar como meros elementos numéricos que nos ofrezcan la fuerza cuantitativa de un grupo parlamentario, carentes de toda capacidad.

\section{B) Jurisprudencia constitucional: representación politica y ius in officium}

No debe olvidarse tampoco, a la hora de abordar la posición actual del parlamentario individual, la íntima conexión reconocida por la jurisprudencia constitucional entre los dos apartados del artículo 23, de forma que «los representantes dan efectividad al derecho de los ciudadanos a participar» (STC 5/1983, FJ 4), y que en consecuencia defender el ejercicio de sus funciones por los representantes parlamentarios «comporta defender también el derecho mismo a participar a través de la institución de la representación en los asuntos públicos» (STC 161/1988, FJ 6).

Como es sabido, aunque el Tribunal Constitucional conecta los dos derechos recogidos en el artículo 23 de la Constitución, señalando que se presuponen mutuamente y pueden ser considerados como modalidades o vertientes del mismo principio de representación política (STC 71/1989, FJ 3), reconoce que son susceptibles de tratamiento autónomo, y así ha desarrollado en torno al derecho de acceso a los cargos públicos proclamado en el apartado 2, además del derecho a permanecer en el cargo, su doctrina sobre el ius in officium del parlamentario.

En lo que aquí nos interesa, y de forma muy esquemática ${ }^{37}$, como resume el Tribunal Constitucional en la sentencia 39/2008, FJ 5 - tomando como base la sentencia

36 F. FERNÁNDEZ SEGADO, «Partidos políticos, representación parlamentaria e interdicción del mandato imperativo», $R C G \mathrm{n}^{\circ} 32,1994$, pág. 73.

37 Puede verse un resumen de la evolución jurisprudencial en la interpretación del artículo 23.2, por todos, en G. ARRUEGO RODRÍGUEZ, Representación politica y derecho fundamental, cit., págs. 193 y ss. 
141/2007_, «el artículo 23.2 CE, además del derecho de acceso en condiciones de igualdad a las funciones y cargos públicos incorpora, como «garantía añadida», el derecho de los parlamentarios y de los grupos en que se integran a ejercer sus funciones en condiciones de igualdad y dentro de la legalidad parlamentaria». Se caracteriza así el «ius in officium tutelado por el artículo 23.2 CE como un derecho de configuración legal, en el sentido de que «compete a los Reglamentos parlamentarios fijar y ordenar los derechos y atribuciones que a los parlamentarios corresponden» (STC 141/2007, de 18 de junio, FJ 3)». «El correlato lógico de esta función configuradora que desempeñan los Reglamentos parlamentarios radica en que una vez creados los derechos y facultades de los parlamentarios, se integran en su status representativo; de modo que, conforme a la doctrina de este Tribunal, «la Constitución veta la privación o perturbación al representante político de la práctica de su cargo, introduciendo obstáculos que puedan colocar a unos representantes en condiciones de inferioridad respecto de otros (SSTC 10/1983; 32/1985, de 6 de marzo, FJ 3; 227/2004, de 29 de noviembre, FJ 2)» (STC 141/2007, de 18 de junio, FJ 5). Lo dicho no conlleva, por otra parte, que cualquier infracción del estatuto del parlamentario en la Cámara represente por sí sola una lesión del derecho fundamental toda vez que únicamente poseen relevancia constitucional aquellos derechos o facultades que pertenezcan al núcleo de la función representativa parlamentaria, respecto de los cuales cabría apreciar vulneración del artículo $23.2 \mathrm{CE}$ «si los propios órganos de las Asambleas impiden o coartan ilegítimamente su práctica o adoptan decisiones jurídicamente reprobables que contraríen la naturaleza de la representación o la igualdad de los representantes (SSTC 38/1999, de 22 de marzo, FJ 2; 107/2001, de 23 de abril, FJ 3; 203/2001, de 15 de octubre, FJ 2, y ATC 118/1999, de 10 de mayo)» (STC 141/2007, FJ 3).

Entre las facultades de los parlamentarios que el Alto Tribunal ha declarado forman parte del citado núcleo de la función representativa parlamentaria, podemos destacar, a efectos del tema que nos ocupa, ${ }^{38}$ el derecho a la iniciativa legislativa mediante la presentación de proposiciones de ley (sentencias 124/1995, 38/1999 FJ 3, 242/2006 FJ 5), el derecho a presentar enmiendas (ATC118/1999: "pues la participación en el ejercicio de la función legislativa y el desempeño de los derechos y facultades que la acompañan constituyen una manifestación constitucionalmente, relevante del ius in officium del representante [STC 38/1990, fundamento jurídico 3..$^{\circ}$ a)]» y más recientemente la importatante STC 119/2011) $)^{39}$ y el derecho al voto de los parlamentarios, como forma más habitual de participar en las tareas de las Cámaras (STC 361/2006, FJ3).

38 Otras facultades que también forman parte de dicho núcleo son las de constituir grupo parlamentario (STC 141/2007, FJ 4), presentar solicitudes de información (161/1988 FJ 7 y STC de 3 de mayo 2011, FJ 4) y solicitudes de comparecencia (177/2002 FJ 5, 208/2003 FJ 5, 90/2005 FJ 3, 74/2009 FJ 4, 190/2009 FJ 3 , 33/2010 FJ 5), así como diversos instrumentos de control (preguntas, 107/2001 FJ 4, 74/2009 FJ 3, 33/2010 FJ 4, 44/2010 FJ 4; interpelaciones, 225/1992; mociones o proposiciones no de ley, 40/2003 FJ 3, 78/2006 FJ3, 44/2010 FJ 5), mientras que no integran el mismo los derechos económicos de los parlamentarios (96/1988 FJ 3, 141/2007 FJ 4).

39 No obstante, el ATC 12/1986 parece dar por bueno que las enmiendas deban presentarse por los grupos parlamentarios: «en ningún caso podría entenderse... que entre aquellas facultades [de los parlamentarios en el ejercicio de sus funciones de representación] se hallan las de presentar enmiendas individuales y no sólo a través del correspondiente Grupo parlamentario... máxime cuando ... ni se impide en absoluto a los diputados formular sus enmiendas, aunque éstas deban ser aceptadas y presentadas por el grupo parlamentario, ni 
De la posibilidad de intervenir en los debates parlamentarios, dice la sentencia 141/2007 (FJ 4) que no cabe duda de que está directamente relacionada con el núcleo de la función representativa, como instrumento de deliberación, expresión de las propias posturas y control del Gobierno, aunque se trata de un ámbito en el que cobra especial relevancia la autonomía parlamentaria, de forma que en esta materia la jurisdicción del Alto Tribunal sólo puede extenderse de manera excepcional y de conformidad con el principio de mínima intervención, para la estricta garantía de los derechos fundamentales de los parlamentarios. La STC 9/2011 (FJ 9)confirma que la posibilidad de intervenir en los debates legislativos forma parte del núcleo de la función representativa.

Volveremos sobre el significado de esta doctrina al examinar la participación de los parlamentarios en las distintas fases y momentos del procedimiento legislativo.

Una última cuestión que puede resultar de interés es la relativa al reconocimiento de la representación que ostentan los grupos parlamentarios, siendo doctrina consolidada que los grupos parlamentarios ostentan una representación institucional de los miembros que los integran que les otorga capacidad procesal ante el Tribunal Constitucional para defender las eventuales vulneraciones de los derechos fundamentales de dichos miembros que tengan relación con el ejercicio de su cargo representativo, aunque — continúa la sentencia 74/2009, FJ 2 - resulta indudable que el reconocimiento de esta representación en ningún caso puede privar de legitimación a los propios diputados que, individualmente, son los titulares del derecho fundamental del artículo 23.2 de la Constitución, derecho que también se vulnera cuando se restringen de manera ilegitima las facultades reglamentarias reconocidas al grupo parlamentario en el que se integran.

\section{FACULTADES REGLAMENTARIAS DE PARLAMENTARIOS Y GRUPOS}

Podemos apreciar en el tratamiento de los grupos parlamentarios en el seno del Parlamento una evolución similar a la descrita por Von Triepel respecto de los partidos políticos (oposición, ignorancia, legalización, constitucionalización), que llega a convertirlos en los protagonistas de la vida parlamentaria, en detrimento de los parlamentarios, de forma que la grupocracia imperante sería el reflejo parlamentario de la partitocracia o gobierno de los partidos políticos que se da en la vida política general.

Además, y aunque los grupos parlamentarios constituyen el origen de los partidos políticos, existe hoy un predominio del partido sobre el grupo parlamentario, hasta el punto de que se identifican en su organización y liderazgo.

consta que al hoy recurrente le fueran rechazadas efectivamente las que, según dice, tenía intención de presentar... Por lo demás, siendo [los grupos]...emanación de los partidos políticos, no puede olvidarse que los mismos se definen en el art. 6 de la Constitución como instrumentos o cauces fundamentales para la participación política, por lo que ni siquiera carecen de cierta justificación en el propio texto constitucional las decisiones adoptadas por el Presidente y la Junta de Portavoces del Congreso de los diputados que ahora se impugnan». 
El reconocimiento jurídico de los grupos parlamentarios es tardío: hasta 1914 y 1921 no empiezan a aparecer en los Reglamentos parlamentarios de Francia e Italia en la composición de las Comisiones. En España, aunque existían desde 1812, se recogen por primera vez en el Reglamento de 1838 (art. 57) las fracciones (denominación que reciben los grupos en el Parlamento alemán) en que se dividían las Comisiones. Su reconocimiento constitucional sería en 1931, al regular la Diputación Permanente, como ocurre también en la actual. Sus funciones se desarrollaban en el Estatuto Provisional de las Cortes de 1934.

Ya hemos visto que en la Constitución de 1978 aparecen citados sólo dos veces. Son los Reglamentos los que reconocen la mayor parte de las iniciativas parlamentarias a los grupos parlamentarios, salvo las de carácter muy marcadamente individual, como las preguntas (que, sin embargo, sin exigencia reglamentaria, llevan de facto la firma del portavoz). El hecho de que incluso las enmiendas deban incluir en el Congreso de los Diputados la firma del portavoz es un ejemplo simbólico del excesivo peso de los grupos parlamentarios en el funcionamiento y organización de las Cámaras, en detrimento del parlamentario individual, que nos lleva a cuestionarnos si esa subordinación absoluta del diputado/senador al grupo parlamentario no quiebra la prohibición de mandato imperativo contenida en el artículo 67.2 de la Constitución, planteada no ya en relación con los electores, sino con los partidos políticos, en la medida en que también la disciplina de grupo quiebra el carácter del voto personal e indelegable que proclama el artículo 79 de la Constitución Española.

Veamos hasta qué punto el reconocimiento reglamentario de facultades de ejercicio de las funciones parlamentarias a los grupos y no a los parlamentarios constituye una manifestación del predominio de los primeros:

El debate se ha convertido en un debate reglado y no libre, con turnos reconocidos sólo a los portavoces (74.2 y 75 RC, 86 RS). Aunque el artículo 84.1 del Reglamento del Senado establece que todo senador puede intervenir una vez que haya pedido y obtenido la palabra, en un debate reglado sólo puede hablar en nombre de su grupo. Apenas el artículo 66.3 del Reglamento del Senado permite abrir una deliberación con intervención de los senadores asistentes en las sesiones informativas de las comisiones, del que se hace escaso uso, previsión contenida también en el artículo 203.3 del Reglamento del Congreso para «casos excepcionales», a juicio del Presidente, de acuerdo con la Mesa y oída la Junta de Portavoces. Volveremos sobre ello al tratar del debate en el procedimiento legislativo.

El artículo 87.1 de la Constitución atribuye la iniciativa legislativa al Congreso y el Senado, «de conformidad con la Constitución y los Reglamentos de las Cámaras». Los Reglamentos la reconocen a un grupo parlamentario o a un número de diputados, quince en el Congreso de los Diputados y veinticinco en el Senado (126.1 RC, 108 $\mathrm{RS})$.

La iniciativa para la reforma de los Reglamentos es similar a la iniciativa legislativa (disposición final $2^{\mathrm{a}} \mathrm{RC}, 196 \mathrm{RS}$ ).

La iniciativa para la reforma de la Constitución corresponde, en el Congreso de los Diputados a dos grupos parlamentarios o a la quinta parte de los diputados (146.1 $\mathrm{RC}$ ); en el Senado, a cincuenta senadores pertenecientes a distintos grupos parlamentarios (152 RS). 
La facultad de enmienda a los textos legislativos se reconoce, como veremos, a parlamentarios y grupos (110.1 RC, 107.1 RS); en el Congreso de los Diputados se precisa la firma del portavoz en las enmiendas «a los solos efectos de conocimiento». En esta Cámara, sólo los grupos pueden presentar enmiendas a la totalidad (110.3 RC) y votos particulares para la defensa en Pleno de las enmiendas al articulado (117 RC), lo que puede cerrar el paso a la voluntad del parlamentario individual.

En la función de control, preguntas (185 RC, 160 RS) e interpelaciones (180 RC, 170 RS) constituyen de iure el único caso en que el parlamentario individual mantiene su iniciativa -igualmente reconocida a los grupos para las interpelaciones en el Congreso- pero de facto las preguntas también van firmadas por el portavoz y son los grupos quienes suscriben las interpelaciones. Los cupos para la inclusión de unas y otras en el orden del día del Pleno (conforme a las reglas aprobadas por la Junta de Portavoces al inicio de cada legislatura) se calculan en función de la importancia numérica del grupo parlamentario, otorgándoles además el derecho de decidir el orden de inclusión de las preguntas presentadas por miembros de su grupo.

Para las peticiones de informe a las Administraciones Públicas, el artículo 7 del Reglamento del Congreso requiere el previo conocimiento del respectivo grupo parlamentario, que se acredita mediante la firma del portavoz. El nuevo artículo 20.2 del Reglamento del Senado (fruto de la reforma de 3 de noviembre de 2004) también incorpora esta exigencia. La STC 57/2011 a que nos referimos a continuación se refiere a la interpretación que de ella realiza la Mesa del Congreso en un supuesto concreto.

De lo expuesto se desprende una omnipresencia de los grupos parlamentarios en las normas reglamentarias y en su aplicación. La creciente atribución de competencias a los grupos parlamentarios y la limitación del ejercicio de sus funciones a los diputa$\operatorname{dos}^{40}$ parece que ha de llevarnos a clamar contra algo que tal vez sea irremediable, pero que debe ser objeto de reflexión para que la Cámara no se convierta en algo inútil, perfectamente sustituible por unos portavoces con voto ponderado en función de los resultados electorales, teniendo en cuenta además que la disciplina del grupo — con aplicación de sanciones económicas por inasistencia o por quebrantar la disciplina de voto- puede coartar realmente la posibilidad de libre ejercicio de su función por los parlamentarios individuales.

Es en este punto donde cobra relevancia la reciente sentencia 57/2011, de 3 de mayo. El Tribunal Constitucional avala el requisito reglamentario, para las peticiones de informe, del previo conocimiento por parte del grupo parlamentario, que «en-

40 Que no es obviamente patrimonio exclusivo de nuestra realidad política. Así, J. C. MASCLET (Le rôle du député et ses attaches institutionnelles sous la Ve République, cit., pág. 142) señalaba ya en 1979 que la iniciativa de los electos y su participación en los trabajos parlamentarios se desarrolla en un contexto muy diferente del existente a comienzos del siglo XX, pues ambas adoptan cada vez más un carácter colectivo. Actuando a continuación la disciplina de voto, generalmente es posible conocer el resultado de un debate en cuanto se hacen públicas las posiciones públicas de los grupos (con las señaladas excepciones de los supuestos en los que los grupos conceden a sus miembros libertad de voto o cuando el resultado es disputado). «La decisión no es el resultado del voto imprevisible de varios centenares de individualidades influidas en su alma y su conciencia por los argumentos esgrimidos en comisión y luego en Pleno. Aquella resulta de la negociación previa realizada a nivel de grupos. El diálogo en sesión pública no hace sino confirmar decisiones previamente adoptadas, registrar un resultado obtenido con anterioridad. Esta es la causa del desinterés por la sesión plenaria, cuyas manifestaciones irritan tanto a la opinión pública». 
cuentra plena justificación en la configuración de los grupos en los actuales Parlamentos, y, en concreto, en el Congreso de los Diputados, como entes imprescindibles y principales en la organización y funcionamiento de la Cámara (por todas, STC 64/2002, de 11 de marzo, FJ 3)», y que «constituye una exigencia acorde con la trascendencia de los grupos en la dinámica parlamentaria y la necesidad de conocimiento y de coordinación, por estos, de las actividades de quienes los integran» (FJ 4). Debidamente interpretado, afirma el Tribunal Constitucional, este requisito no limita el ius in officium del representante.

Se parte de la base de que la capacidad de solicitar la información forma parte del ius in officium del parlamentario, pues se trata de una función parlamentaria de posible ejercicio individual, claramente instrumental respecto de las facultades de los diputados de control al Gobierno (a través de interpelaciones y preguntas), que en consecuencia forma parte del derecho fundamental garantizado en el artículo 23 de la Constitución.

El Tribunal examina la motivación de los acuerdos impugnados, que situaban en la práctica parlamentaria precedente la acreditación del conocimiento por el grupo con la firma del portavoz en el texto de la iniciativa, y concluye que la invocación de este precedente parlamentario carece de virtualidad limitadora de las prerrogativas públicas reconocidas por el Reglamento de la Cámara, limitación que de hecho se produce al establecer un único cauce para el cumplimiento de la obligación ${ }^{41}$.

Sin embargo, el Tribunal Constitucional no sólo da por bueno el requisito de previo conocimiento del grupo parlamentario respecto de este tipo de iniciativas, sino también las restricciones reglamentarias expresas a la presentación de enmiendas por los parlamentarios - exigencia de la firma del portavoz, cuya posible aplicación analógica a las solicitudes de informe rechaza por carecer de previsión reglamentaria-e incluso la hipótesis de que «los órganos competentes de la Cámara establecieran la forma precisa o cauce concreto a seguir para asegurar la efectividad de la comunicación al grupo parlamentario», concreción que, «no obstante, tendría que encontrar justificación en el buen gobierno y gestión del procedimiento y no definirse conforme a fórmulas que hiciesen depender la tramitación de la iniciativa a una suerte de autorización al diputado titular del derecho por parte del destinatario de la comunicación» (FJ 7).

Sabemos que el ius in officium es un derecho de configuración legal, pero la sentencia no parece poner gran empeño en reivindicar el papel del parlamentario individual frente al grupo parlamentario en el ejercicio de las funciones constitucionales.

41 «Se introduce, en definitiva, una restricción en el ejercicio de la iniciativa parlamentaria que carece de suficiente justificación y que, además, recorta con intensidad la facultad prevista en el Reglamento, pues la negativa del portavoz a la firma, por la razón que fuere, impediría la efectividad del derecho reconocido individualmente al Diputado, con el resultado de que vendría a alterarse el régimen previsto en la norma reglamentaria, que no establece como condición para la tramitación de la iniciativa una firma o una autorización por parte del grupo parlamentario». «La forma en que la Mesa del Congreso de los Diputados entiende el requisito controvertido no responde al principio de interpretación más favorable a la eficacia de los derechos fundamentales.....No habiendo restricción expresa en el Reglamento del Congreso de los Diputados para el empleo de otras fórmulas para la puesta en conocimiento del grupo de la iniciativa del diputado, no sólo se desatendió el principio de interpretación más favorable a la eficacia del derecho, sino que, además, «los acuerdos cuestionados optaron por la interpretación más lesiva» del mismo, ya que condujeron a una limitación de su efectividad pese al amplio margen que la norma reglamentaria ofrece para acoger otras opciones acordes con el sentido de dicha norma» (FJ 7). 


\section{PARLAMENTARIOS Y GRUPOS EN EL PROCEDIMIENTO LEGISLATIVO}

\section{A) La función legislativa como expresión de la voluntad general}

Vistas las normas reglamentarias que configuran las facultades de parlamentarios y grupos en los diferentes procedimientos, podemos centrarnos en su intervención en la función legislativa, la función por antonomasia de las asambleas representativas, que significa la participación de los representantes elegidos por el pueblo soberano en la formación de la voluntad general, expresada en la ley.

Recordemos que, aunque no sea la que se encuentra en el origen de los Parlamentos (siendo ésta la función financiera o presupuestaria) y hoy se discute si no ha sido sustituida en importancia por la función de control del Gobierno, la función legislativa constituye la función esencial y primaria del Parlamento, y como tal aparece enunciada en primer lugar por el apartado segundo del artículo 66 de la Constitución (precepto que abre el título dedicado a las Cortes Generales): «las Cortes Generales ejercen la potestad legislativa del Estado».

En ocasiones se trata de minimizar la función legislativa del Parlamento en el Estado contemporáneo, argumentando que aquél no goza del monopolio del poder legislativo, en la medida en que el Gobierno también dicta normas con rango de ley - los decretos leyes y la legislación delegada - y que se ha visto asimismo afectado por las transformaciones en el concepto de ley, que ha perdido sus características de abstracción y generalidad y se ha diversificado en una tipología plural ${ }^{42}$.

Ha de reivindicarse, no obstante, la importancia de la función legislativa del Parlamento ${ }^{43}$. Y ello porque la ley, en la fórmula clásica proclamada en el artículo 6 de la Declaración de Derechos del Hombre y del Ciudadano, constituye la expresión de la voluntad general y de ello deriva el lugar que ocupa en el sistema de las fuentes del Derecho, que, si bien subordinado a la Constitución, es superior al de las demás normas que integran la pirámide del ordenamiento jurídico. Este principio democrático se combina con el representativo ${ }^{44}$, de ahí que se atribuya al Parlamento, integrado por los representantes del pueblo titular de la soberanía, la función legislativa.

42 Véase sobre este punto L.M. DÍEZ-PICAZO, «Concepto de ley y tipos de leyes (¿existe una noción unitaria de ley en la Constitución española?)», REDC, $\mathrm{n}^{\circ}$ 24, 1998, págs. 47 y ss. Defiende el mantenimiento del papel central del Parlamento todavía hoy, B. PENDÁS GARCÍA ( $P$ Procedimiento legislativo y calidad de las leyes», REDC, nº 28, 1990, pág. 79), entendiendo que será capaz de mantener una tensión polémica con el poder ejecutivo predominante, incluso con el partido político hegemónico.

43 I. DE OTTO («La función política de la legislación», en Parlamento y sociedad civil, Universidad de Barcelona, Barcelona, 1980, pág. 49) señala cómo de las tres posibles funciones del Parlamento, órgano de creación, órgano de control y órgano de legislación, la tercera es hoy la más importante o, cuando menos, es la función en la que los parlamentarios modernos han visto menos mermada su importancia en el sistema político. Según De Otto, esto aparece muy claramente en la Constitución española (como en otras europeas de democracia parlamentaria) en la que el poder constituyente ha minimizado las funciones de control y creación del poder parlamentario y lo ha reducido a la función legisladora.

44 Como recuerda F. RUBIO LLORENTE («El Parlamento y la representación política», en I Jornadas de Derecho Parlamentario, Congreso de los Diputados, Madrid, 1985, pág. 149), de acuerdo con la concepción clásica de Sieyès, repetido después con variantes en Schumpeter y que tiene expresión clásica en la teoría del Estado en la obra de Hans Kelsen, la representación política es la resultante de la actuación conjunta de dos principios distintos: el principio democrático, de una parte, y el principio de división del trabajo, de la otra. 
Sobre este punto estriba, como ha puesto de relieve acertadamente Garrorena, la diferente cualidad de la ley respecto del reglamento, como productos que son de dos potestades cualitativamente diferentes: sólo a la naturaleza de la ley pertenece el ser expresión de la voluntad soberana del Estado; sólo detrás de ella está el Parlamento como representación de la sociedad y, en consecuencia, sólo sus mandatos producen decisiones de soberanía ${ }^{45}$.

La función legislativa del Parlamento se identifica con un determinado procedimiento de actuación parlamentaria, el procedimiento legislativo, de forma que, aunque hoy no sea enteramente cierto que la legislación es sólo un procedimiento, sí lo sería que la legislación es, sobre todo, un determinado procedimiento ${ }^{46}$. Así, dice Rubio Llorente que lo que define a la potestad legislativa no es ya su función ni su origen, sino su método, su procedimiento, el debate público, la publicidad ${ }^{47}$.

La evolución del concepto de ley, el abandono del concepto de ley material y la multiplicación de los tipos de ley en las Constituciones recientes conducen, entre otras causas, a la importancia actual del procedimiento legislativo. Al prescindir del contenido, el principal elemento definidor de la ley es el haber sido adoptada conforme a los procedimientos fijados por la Constitución y el Reglamento parlamentario ${ }^{48}$. De manera que el procedimiento supera su función inicial de ordenar los trabajos de la Cámara, para ser garantía de la participación de todos los grupos parlamentarios en la formación de la ley y del carácter democrático de las decisiones del Parlamento. En este sentido, la reserva a la ley de determinadas materias no significa sólo la reserva al órgano más directamente democrático, sino también al órgano que, por contener la representación de la pluralidad de opciones políticas, permite que todas ellas (y no sólo la mayoritaria) participen en la elaboración de la norma. Se trata, por tanto, de la reserva a un determinado procedimiento de emanación normativa (el procedimiento legislativo parlamentario), dotado de las características de contradicción, publicidad y libre deliberación que le son propias y que lo diferencian sustancialmente del procedimiento de elaboración normativa gubernamental.

En este sentido, De Otto ${ }^{49}$ considera que el lugar central que la ley ocupa en el ordenamiento jurídico no se debe sólo a que sea obra de las Cortes Generales que representan al pueblo español (art. 66.1), sino también a que su elaboración se sujeta a un procedimiento basado en la discusión y en la publicidad y concebido originariamente como cauce para alcanzar la racionalidad y la verdad, de acuerdo con la confianza que el liberalismo pone en el libre debate. Incluso aunque se critique la vigencia de estas afirma-

45 A. GARRORENA MORALES, El lugar de la Ley en la Constitución española, CEC, Madrid, 1980, pág. 97. De ahí que la Constitución realice la identificación de ley y de reglamento precisamente por referencia a las potestades de que son fruto; en el artículo 97 cita la potestad reglamentaria, en el artículo 66.2, la potestad legislativa (pág. 99).

46 Ibidem, pág. 135.

47 F. RUBIO LLORENTE, «Función legislativa, poder legislativo y garantía del procedimiento legislativo», en El procedimiento legislativo. V Jornadas de Derecho parlamentario, Congreso de los Diputados, Madrid, 1997, pág. 30.

48 E. AJA FERNÁNDEZ, «Caracteres y principios generales del procedimiento legislativo» Anuari de Dret Politic, Universidad de Barcelona, Barcelona, 1983, págs. 159-160.

49 I. DE OTTO, Derecho Constitucional. Sistema de fuentes, Ariel, Barcelona, 1987, pág. 106. Véase también M. ARAGÓN REYES, «La función legislativa de los parlamentos y sus problemas actuales», en El Parlamento y sus transformaciones actuales, A. GARRORENA MORALES Ed., Tecnos Madrid, 1988, pág. 136. 
ciones y hayan de considerarse justificadas las propuestas de reforma, el procedimiento seguiría cumpliendo una imprescindible función legitimadora de la ley, precisamente por obra de los mecanismos de pluralidad y discusión que lo hacen técnicamente tan defectuoso y complejo.

Así pues, el procedimiento legislativo presenta dos finalidades o vertientes básicas, la política y la técnica. La primera pretende asegurar la participación de las distintas opciones políticas en la elaboración de la ley, mediante su participación o integración en el procedimiento, a lo largo del cual se procura concitar el mayor grado posible de acuerdo en torno a un texto.

La vertiente técnica muestra cómo el procedimiento persigue también que, a lo largo de sus distintas fases, el texto vaya depurándose desde un punto de vista técnico, de forma que al término de aquél la ley sea lo más perfecta posible, tanto desde un punto de vista formal como material, adecuándose lo más plenamente posible a los fines que persigue. Este segundo aspecto constituye el objeto de la técnica legislativa, que no sólo se refiere a los caracteres formales de las leyes, sino a su eficacia para conseguir los objetivos que se desean obtener con su aprobación. Quede sólo apuntada la importancia y significado de la técnica legislativa, porque detenernos aquí nos desviaría de nuestro objeto de estudio ${ }^{50}$.

La función política o integradora del procedimiento legislativo inspira (como también la técnica) todas las fases de desarrollo del mismo. Como órgano colegiado, el Parlamento necesita de un procedimiento que le permita articular su voluntad. Pero, además, como órgano representativo, el procedimiento cumple una función de integración. No basta con que en el texto final de la ley se exprese la voluntad de la mayoría, sino que se pretende que a lo largo de su debate participe y se exprese la voluntad de la minoría, con la debida publicidad ${ }^{51}$. Ésta es la consecuencia del carácter representativo del Parlamento, que se manifiesta doblemente: de una parte, se trata de asegurar la participación de las minorías a lo largo de todo el procedimiento legislativo, y ello es necesario porque, como señala García Martínez, ${ }^{52}$ éste cambia continuamente de objeto, siendo distinto el texto objeto del debate en cada una de las fases (ponencia, comisión y Pleno), de ahí que la elección de los miembros de dirección de las Cámaras y los turnos de intervención intenten garantizar esa presencia continua de las minorías; en segundo lugar, la función de representación lleva aparejada la publicidad de la actuación del órgano representativo por excelencia, el Pleno de las Cámaras.

50 He tenido ocasión de ocuparme del tema en otras ocasiones: en referencia a la fase inicial del procedimiento legislativo, P. GARCÍA-ESCUDERO MÁRQUEZ, La iniciativa legislativa del Gobierno, cit., págs. 86100. Pueden consultarse también «Nociones de técnica legislativa para uso parlamentario», Asamblea, $\mathrm{n}^{\circ} 13$, 2005, y Técnica legislativa y seguridad jurídica, Civitas, Madrid, 2010.

51 De acuerdo con el principio parlamentario the majority shall have its way, the minority its say. No obstante, P. BIGLINO CAMPOS («Veinticinco años de procedimiento legislativo», RDP, n 58-59, 2003-2004, págs. 456-457) alerta del peligro que la fuerza de la mayoría puede suponer para el pluralismo: aunque deba tener la última palabra, no debe convertir el conjunto del procedimiento en papel mojado: la fuerza de la mayoría arranca de las elecciones, pero la legitimidad de su ejercicio radica, quizás, en reconocer que la minoría no siempre se equivoca.

52 M. ${ }^{a}$ A. GARCÍA MARTÍNEZ, «La actividad legislativa del Parlamento como mecanismo de control político», RCG, nº 14, 1988, págs. 73-74. 


\section{Intervención en el procedimiento}

$\mathrm{Al}$ igual que ocurre con otros procedimientos, el legislativo muestra un protagonismo absoluto de los grupos parlamentarios sobre los parlamentarios individuales. Este fenómeno ha sido obviamente fruto de la regulación contenida en los Reglamentos - pues las dos menciones constitucionales a los grupos no afectan al procedimiento que nos ocupa- al igual que en otros a través de los que se articula el ejercicio de las funciones de las Cámaras.

El protagonismo de los grupos parlamentarios en el procedimiento legislativo se manifiesta en las distintas fases del mismo, a pesar de que las facultades que en ellas se ejercen forman parte del núcleo esencial del ius in officium del parlamentario: el Tribunal Constitucional ha afirmado (STC 38/1999, FJ 3) que la participación en el ejercicio de la función legislativa por los representantes de los ciudadanos (máxima expresión del ejercicio de la soberanía popular en el Estado democrático) y en el ejercicio de los derechos y facultades que la acompañan constituyen una manifestación constitucionalmente relevante del ius in officium del representante. Perturbado o coartado éste, se perturba y coarta la participación de los ciudadanos en los asuntos públicos, infringiendo así el artículo 23. 1 y 2 de la Constitución.

Hemos visto cómo el Tribunal ha señalado como derechos o facultades que indudablemente pertenecen al núcleo de la función representativa parlamentaria — cuya perturbación lo es también del derecho de participación de los ciudadanos- la presentación de proposiciones de ley (sentencias 124/1995 FJ 3, 38/1999 FJ3 y 242/2006 FJ 5) o enmiendas (ATC 118/1999), como también el derecho a participar en los debates parlamentarios (sentencia 141/2007, FJ 3) y a votar (361/2006).

Examinemos a continuación con mayor detenimiento la participación de los parlamentarios en el procedimiento legislativo en la normativa reglamentaria y en la realidad, para ver hasta dónde llega su intervención en el ejercicio de la función legislativa de las Cámaras.

\section{a) Facultad de iniciativa}

La sentencia 124/1995 FJ 3, en la que el Tribunal se pronuncia por primera vez sobre la inadmisión de una proposición de ley por parte de la Mesa de un Parlamento autonómico, declara que las proposiciones de ley promovidas por los Grupos Parlamentarios no sólo son una forma — sin duda, la más señalada y expresiva_ de participación de los parlamentarios en la potestad legislativa de las Cámaras parlamentarias. Son también un cauce instrumental al servicio de la función representativa característica de todo Parlamento, operando como un instrumento eficaz en manos de los distintos grupos políticos que integran el Pleno de la Cámara, y que les permite obligar a que éste se pronuncie acerca de la oportunidad de la iniciativa presentada.

La iniciativa legislativa está reconocida, en el ámbito parlamentario, además de a un grupo parlamentario, a un número de miembros de la Cámara, quince en el Reglamento del Congreso (art. 126.1) y veinticinco en el Reglamento del Senado, art. 108.1 (también a la Comisión General de las Comunidades Autónomas, en esta Cámara). 
Aunque los Reglamentos ${ }^{53}$ reconocen la facultad de presentar proposiciones de ley a parlamentarios y grupos, el protagonismo creciente de éstos los ha convertido en únicos autores de estas iniciativas. No obstante, hasta la IX legislatura que se inicia en marzo de 2008, en consideración a la posibilidad de proposiciones de parlamentarios, no se aplicaba a la inclusión de su toma en consideración en el orden del día del Pleno del Congreso el sistema de cupo entre los grupos en función de su importancia numérica que rige para otras iniciativas (proposiciones no de ley, preguntas), sino el principio temporal, incluyéndose aquéllas según el criterio cronológico de orden de presentación en el Registro. Eso sí, con dos puntualizaciones que hacían augurar un posible cambio en el Congreso hacia la aplicación del criterio de cupo $^{54}$ (tampoco aplicado en el Senado, en este caso por innecesario, porque no suelen acumularse proposiciones pendientes de tramitación): sólo se incluía una por grupo parlamentario, correspondiendo, por tanto, la inclusión a los dos grupos que aparecieran como primeros autores en la lista de proposiciones de ley pendientes de toma en consideración; y el grupo autor de la proposición podía solicitar, y obtener prácticamente siempre ${ }^{55}$, la conformidad de los grupos restantes para cambiar la proposición de ley de su autoría que desea incluir. Es decir, salvo oposición, las proposiciones de un mismo grupo son intercambiables, pasando en la lista la que ocupaba el primer lugar al de aquélla que se incluye en el orden del día. Al inicio de la IX legislatura, por acuerdo de la Junta de Portavoces de 2 de julio de 2008, se aplica a la inclusión en el orden del día de las proposiciones presentadas por los grupos parlamentarios el sistema de cupo resultante de asignar a cada grupo una proposición por cada diez diputados o fracción pertenecientes al mismo.

\section{b) Facultad de presentar enmiendas}

Son los grupos los que gozan en plenitud de la facultad de presentación de enmiendas, como señala Rubio Llorente ${ }^{56}$. En efecto, aunque pueden presentar enmiendas — según el artículo 110.1 del Reglamento del Congreso- los diputados y los grupos parlamenta$\operatorname{rios}^{57}$, han de hacerse algunas matizaciones a esta afirmación general: la presentación de

53 Y no la Constitución, a diferencia de otras de nuestro entorno: italiana, francesa y portuguesa. El artículo 87 de nuestra Carta Magna remite a los Reglamentos la regulación de la iniciativa parlamentaria.

$54 \mathrm{Al}$ inicio de la VIII legislatura, la presentación de gran número de proposiciones de ley, desde la misma sesión constitutiva del Congreso, por distintos grupos parlamentarios (CiU, ERC, posteriormente IU-IVICV), impidió el debate de una sola proposición de ley del Grupo Popular, principal grupo de la oposición, durante el primer período de sesiones, hasta junio de 2004 incluido, y gran parte del siguiente.

55 Como excepción a esta regla, se denegó — por ejemplo_ la permuta que permitiera incluir la proposición del Grupo Socialista sobre regulación de la interrupción voluntaria del embarazo en tres ocasiones, entre mayo y junio de 1998, por oposición del Grupo Popular.

56 F. RUBIO LLORENTE, «El procedimiento legislativo en España: el lugar de la ley entre las fuentes del Derecho», REDC, no 16, 1986, pág. 94.

57 No existe limitación alguna para que las enmiendas provengan de grupos distintos al autor de la iniciativa, siendo frecuentes las llamadas «autoenmiendas», especialmente de carácter transaccional. De ellas se olvida la definición de enmienda de P. BIGLINO CAMPOS («Enmienda en el procedimiento legislativo», en Enciclopedia jurídica básica, vol. II, Civitas, Madrid, 1995, pág. 2803) como «las propuestas mediante las cuales se pretende influir en las iniciativas legislativas que provienen de otros titulares, solicitando su rechazo, su modificación total o parcial o la adición de cuestiones no previstas». Las autoenmiendas son muy frecuentes, sobre todo en fases poste- 
enmiendas por los diputados requiere, según el Reglamento del Congreso (art. 110.1), la firma del portavoz del grupo a que pertenezca "a los meros efectos de conocimiento» ${ }^{58}$, trámite cuya omisión puede subsanarse antes del comienzo de la discusión en la Comisión; y las enmiendas a la totalidad sólo pueden ser presentadas por los grupos parlamentarios (art. 110.3);

Puede apreciarse que ambos supuestos constituyen limitaciones al derecho de enmienda de los diputados en favor de los grupos parlamentarios, en la línea general antes expuesta, pese a que las enmiendas y las preguntas son las iniciativas parlamentarias de carácter más genuinamente individual, y puede decirse que las únicas que los Reglamentos continúan reconociendo a los diputados.

Como dice García Roca, participar en la elaboración de las leyes ha sido históricamente la razón de ser de los parlamentarios como representantes de los ciudadanos, y sin embargo no hay una previsión constitucional expresa acerca de la enmienda como un derecho individual. Pero la necesidad de su reconocimiento también en esos términos debe deducirse de su puesta en conexión con el artículo 23.2 de la Constitución, a través de una interpretación finalista en torno a la naturaleza del contenido de la enmienda y a los fines a los que atiende, así como de una interpretación sistemática que lleve a ponderar una articulación lógica y congruente de los distintos mecanismos de la participación en la función legislativa. Recuerda este autor que las enmiendas al articulado son el único medio que permite, de hecho, participar al parlamentario en la función legislativa ${ }^{59}$.

Las enmiendas representan el cauce de participación de los distintos intereses presentes en la Cámara en el procedimiento legislativo, y así lo reconoce el Tribunal Constitucional en el auto 118/1999. Limitar expresamente el derecho de enmienda de los diputados hasta hacerlo desaparecer podría entrar en colisión con su participación en la función legislativa de las Cortes Generales y, por ende, con el ius in officium reconocido en el artículo 23 de la Constitución ${ }^{60}$. Tal vez sea el reconocimiento de este circunstancia la que lleva al Reglamento del Congreso a señalar que la firma del portavoz se exige «a los meros efectos de conocimiento» y a declarar su carácter subsanable ${ }^{61}$.

riores del procedimiento, pero también en el plazo inicial de presentación, si son proposiciones parlamentarias. Puede decirse que materialmente, si no formalmente, tienen también este carácter las enmiendas (a veces muy numerosas) que presenta el grupo que apoya al Gobierno a los proyectos remitidos por éste.

58 Las dos iniciativas parlamentarias más claramente individuales y que los Reglamentos parecen reservar a los parlamentarios (enmiendas y preguntas) se sujetan a la firma del portavoz del grupo, las primeras por imposición reglamentaria, las segundas por la práctica impuesta por los grupos mayores. La firma del portavoz reglamentariamente exigida para las enmiendas, como señala F. RUBIO LLORENTE (ibidem), mediatiza la facultad de enmendar de los diputados, a la vez que refuerza la disciplina interna del grupo.

59 J. García Roca, Cargos públicos representativos. Un estudio del artículo 23 de la Constitución, Aranzadi, Pamplona, 1999, pág. 315.

60 Continúa J. García Roca, ibidem: «La auctoritas y la propia dignidad de la función de los representantes individuales y el interés general en que los concretos parlamentarios participen personalmente en la elaboración de las leyes hacen — a mi juicio_- pensar que no podría excluirse de los Reglamentos parlamentarios esa facultad de enmienda al articulado de ejercicio individual sin que — de no incluirse otras facultades de mayor entidad- dejase de resultar recognoscible el mismo nomen iuris y la posición constitucional del parlamentario en el seno de las funciones legislativas y de control y, en consecuencia, violado el artículo 23.2 de la Constitución».

61 Más correcta es la posición de algunos Reglamentos parlamentarios autonómicos, que, aunque exigen la firma del portavoz, señalan que su ausencia «no prejuzgará la posición del grupo correspondiente sobre la misma» (Navarra) o «determinará la no asunción de la enmienda por el grupo de que se trate, pero no impedirá su tramitación» (Aragón). 
Sea cual sea la finalidad que persigue la firma del portavoz, constituye sin duda un elemento de control del grupo sobre la actividad del diputado en el procedimiento legislativo, pues puede negarle la firma en caso de no conformidad con sus enmiendas, lo que resulta de dudosa constitucionalidad ${ }^{62}$. Sabemos que el artículo 23 CE reconoce un derecho de configuración legal que no puede desarrollarse sin límites, según ha declarado el Tribunal Constitucional (sentencia 181/1989, entre otras). Pero los límites nunca podrían llegar a desvirtuar el contenido del derecho suprimiéndolo o limitándolo hasta hacerlo irreconocible ${ }^{63}$.

García Roca ${ }^{64}$ mantiene que la exigencia de la firma del portavoz no puede confundirse con un control ni formal ni material de las enmiendas por parte del grupo parlamentario, entre otras razones por los términos «a los meros efectos de conocimiento» contenidos en la norma reglamentaria. Pero una cosa es la teoría y otra la realidad, y pueden existir (de hecho, han existido) supuestos de negativa de la firma del grupo a la iniciativa «por libre» de un diputado, o no coincidente con la postura del grupo, que coarten su derecho de enmienda. En tal caso, cabría que la Mesa de la Cámara o la de la Comisión apreciara como suficiente, en el trámite de subsanación a que se refiere el artículo 110.1 RC, la prueba de que la enmienda ha sido puesta en conocimiento del portavoz, para admitir a trámite la enmienda no suscrita por el mismo, es decir, carente de un requisito reglamentario ${ }^{65}$.

62 A. M. ${ }^{a}$ REDONDO GARCÍA (El derecho de enmienda en los procedimientos legislativos de las Cortes Generales, Congreso de los Diputados, Madrid, 2001, págs. 110-111) estima que la exigencia de la firma del portavoz o de un número de parlamentarios obliga a coordinar voluntades en el seno del grupo y facilita, en consecuencia, la actividad legislativa, impidiendo que miembros de la misma formación presenten textos idénticos o de semejante contenido, con lo que se consigue optimizar el trabajo de los propios representantes y limitar el número de intervenciones en los debates. Creemos que este argumento no es suficiente para exigir la firma del portavoz y puede suponer un control de la actividad «legislativa» del diputado. En el mismo sentido, F. SANTAOLALLA LÓPEZ (Derecho parlamentario español, $2^{a}$ ed., Espasa-Calpe, Madrid, 1990, pág. 229): este tipo de disposiciones no obedecen más que al deseo de los grupos parlamentarios de obtener, a través del Reglamento, un instrumento adicional de disciplina de partidos.

63 No obstante, como se ha señalado en nota 42, el ATC 12/1986 inadmite la denuncia de un diputado contra la Resolución de la Presidencia del Congreso que limitaba a los grupos parlamentarios la presentación de enmiendas a un proyecto de ley, señalando que en ningún caso podría entenderse, sin invadir el ámbito reservado a la autonomía de la Cámara, que entre las facultades incluidas en el derecho de participación se hallan las de presentar enmiendas individuales y no sólo a través del correspondiente grupo, con lo que parecía admitir la posibilidad de que la normativa permita presentar enmiendas sólo a los grupos parlamentarios. Es probable que, como dice A.M. ${ }^{a}$ REDONDO GARCÍA ( «La facultad de presentar enmiendas como concreción del derecho fundamental reconocido en el artículo 23.2 de la Constitución», en Parlamento y Justicia Constitucional, Aranzadi, Pamplona, 1997, pag. 386), esta decisión del Tribunal hoy no se produciría en semejantes términos, puesto que la jurisprudencia posterior considera jurídicamente ilícito proceder a una modificación del Reglamento mediante Resolución, sustrayendo tal decisión al Pleno de la Cámara. Asimismo, la STC 27/2000 desestima el recurso de amparo interpuesto por parlamentarios vascos contra el acuerdo de la Mesa del Parlamento Vasco de tramitación por lectura única de un proyecto de ley paccionado entre las Diputaciones Forales y la Comunidad Autónoma, con la consiguiente eliminación de la posibilidad de presentar enmiendas: esta restricción del derecho fundamental no sería desproporcionada, pues el procedimiento «permite diferentes manifestaciones de participación y de iniciativa parlamentaria, tanto en los trámites preliminares como en el momento mismo de la decisión final sobre la aprobación o rechazo del proyecto de ley, suficientes para satisfacer el contenido esencial de los derechos tutelado por el artículo $23 \mathrm{CE}$ » (FJ 6).

64 J. GARCÍA ROCA, Cargos públicos representativos. Un estudio del artículo 23 de la Constitución, cit., pág. 317.

65 En el mismo sentido, A. M. ${ }^{a}$ REDONDO GARCÍA, El derecho de enmienda en los procedimientos legislativos de las Cortes Generales, cit., págs. 118-119, y J. García Roca, ibidem. Hemos comentado supra la sentencia 
Ninguna regla especial se aplica a los miembros del Grupo Mixto, cuyas enmiendas deberán, asimismo, ir suscritas por el portavoz (rotatorio con periodicidad mensual, según la práctica en las últimas legislaturas), lo que tiene aún menos fundamento, tratándose de un grupo en que sus miembros son, por naturaleza, de extracción plural y actuación autónoma ${ }^{66}$.

En todo caso, es frecuente que, entre las medidas que se proponen para la reforma del procedimiento legislativo, se encuentre la supresión de este requisito. Se insertaría esta modificación en la tendencia a reforzar la figura del diputado individual, junto con la previsión de un turno de intervención de éste en determinados debates, considerando suficientemente garantizada la preponderancia de los grupos parlamentarios con su legitimación en exclusiva para la presentación de enmiendas a la totalidad (cuyo carácter de negativa rotunda a la tramitación del texto legislativo puede justificar, como posición política, la autoría de grupo) y de los votos particulares para la defensa de enmiendas al articulado ante el Pleno, de más discutible justificación teórica, pero que puede hallar su fundamento en la necesidad de racionalizar los trabajos de la Cámara ${ }^{67}$.

Por lo demás, la polémica es un poco estéril, desde el momento en que, en el momento actual, las enmiendas — como las proposiciones de ley- son presentadas exclusivamente por los grupos parlamentarios, habiendo desaparecido prácticamente las enmiendas de diputados ${ }^{68}$, con excepción de las del Grupo Mixto, donde se pre-

sobre el supuesto de inadmisión de solicitudes de informe de un diputado por la Mesa del Congreso descrito en nota 30, por no constar la firma del portavoz, aunque se acreditara el conocimiento del grupo por otros medios.

66 La Resolución de la Presidencia del Congreso sobre organización y funcionamiento del Grupo Mixto, de 9 de septiembre de 1986 (BOCG Congreso, Serie E, n 3, de 11 de septiembre de 1986), que creaba la existencia de Agrupaciones en el seno del mismo, permitía al representante de la Agrupación desempeñar las funciones propias del portavoz, entre ellas, suscribir las enmiendas de los miembros de la Agrupación. Asimismo, la Norma interpretativa de la Presidencia del Senado de 9 de septiembre de 1986 (BOCG Senado, Serie I, $n^{\circ}$ 16, de 1 de octubre de 1986) permitía al representante de la Agrupación firmar todas las iniciativas parlamentarias que correspondieran a los grupos de la Cámara de acuerdo con el Reglamento. En los debates sobre la proposición de reforma del Reglamento del Congreso de 1993, el Sr. Mur Bernard defendió una enmienda en la Comisión de Reglamento, en el sentido de suprimir la exigencia de firma del portavoz en las enmiendas de diputados del Grupo Mixto, «dadas sus singularidades y donde cada uno es portavoz de sí mismo», enmienda rechazada sobre la base de la igualdad de derechos entre los grupos parlamentarios (Diario de Sesiones del Congreso, no 655, de 29 de marzo de 1993, pág. 19728).

67 Un argumento similar cabría aplicar a las enmiendas transaccionales presentadas en el curso del debate en Pleno o en Comisión. Respecto de las primeras, el artículo 118.3 del Reglamento del Congreso faculta a los grupos parlamentarios para oponerse a su admisión a trámite. En cambio, en la Comisión (114.3 RC), la presentación se restringe a los miembros de la misma, excluyendo a los restantes parlamentarios (lo que C. Ortega Santiago, El mandato representativo de los diputados y senadores, cit., pág. 275, considera limitador de la esfera de autonomía del diputado). También el Reglamento del Senado faculta sólo a los grupos parlamentarios para la presentación en el Pleno de las llamadas propuestas de modificación del dictamen, pues son los portavoces quienes deben suscribirlas (art. 124.1). Nada se dice respecto de los autores de las enmiendas transaccionales en Comisión (115 RS).

68 Apenas se planteó un caso en la VI legislatura, en la que un diputado presentó unas enmiendas contrarias a la posición de su grupo con su propia firma, como portavoz adjunto (Sr. Serrano Vinué, diputado del Partido Aragonés Regionalista integrado en el Grupo Popular, en relación con el Proyecto de Ley de modificación de la Ley 29/1985, de 2 de agosto, de aguas. Véase Diario de sesiones n ${ }^{\circ} 263$, de 30 de septiembre de 1995, pág. 13995). Posteriormente renunció al escaño. Encontramos también un supuesto de presentación de una enmienda a la totalidad de devolución del Proyecto de Ley por la que se modifica el Código Civil en materia de derecho a contraer matrimonio, por cuatro «diputados de Uniò Democràtica de Catalunya» —según 
sentan por tantos diputados como formaciones lo integran, también con la firma del portavoz.

En el Senado, apreciamos dos diferencias con respecto al Congreso de los Diputados en este punto, a favor de los senadores individuales, los cuales pueden presentar propuestas de veto y no sólo enmiendas al articulado - mientras que los diputados no pueden presentar enmiendas a la totalidad, que quedan reservadas a los grupos por el artículo 110.3 RC - y no precisan de la firma del portavoz para la presentación de sus enmiendas.

Este segundo aspecto (no exigencia de la firma del portavoz) es digno de alabanza, en aras de mantener un margen de libertad y de protagonismo de los parlamentarios, como representantes del pueblo, sobre los grupos políticos a que pertenecen. En cambio, no es tan rechazable que se limite a los grupos parlamentarios la presentación de enmiendas a la totalidad, que no otra cosa son las propuestas de veto ${ }^{69}$, como susceptibles de plantear una oposición global y un debate de este carácter entre formaciones políticas.

\section{c) Presentación de votos particulares}

En el Congreso, los grupos presentan los votos particulares, indicando las enmiendas defendidas no incorporadas al dictamen que desean defender en el Pleno (art. 117 del Reglamento del Congreso), con lo cual pueden cerrar el paso a la voluntad individual de los diputados de defender sus enmiendas.

En efecto, los Reglamentos del Congreso y del Senado (117 RC, 117 RS) establecen un trámite previo a la defensa de enmiendas en el Pleno, exigiendo la comunicación por escrito a la Presidencia de la Cámara de tal propósito, en el plazo de cuarenta y ocho horas desde la fecha de terminación del dictamen (Congreso) o no más tarde del día siguiente de dicha terminación (Senado).

Se inserta así un trámite entre las fases de comisión y de Pleno, de obligada cumplimentación para poder intervenir en defensa de enmiendas en el Pleno de las Cámaras. El objetivo que pretenden los preceptos reglamentarios es conocer las intenciones de los grupos respecto de qué enmiendas consideran deben seguir manteniendo en este momento de la tramitación. Sobre las inicialmente presentadas, no solamente han de entenderse eliminadas aquellas que hayan sido incorporadas al texto por la ponencia o la Comisión ${ }^{70}$, sino

se autodefinían en el escrito-, consecuencia de la distinta postura mantenida respecto de este proyecto por las dos formaciones que integran la coalición electoral Convergencia y Uniò y su correlativo grupo parlamentario. En puridad, como tales diputados, no estaban facultados para la presentación de enmiendas a la totalidad, pero al estar firmada por uno de ellos como Portavoz del Grupo (Durán i Lleida) fue admitida a trámite. Véase BOCG Congreso, Serie A, n ${ }^{\circ} 18-5$, de 15 de marzo de 2005.

69 Así lo reconoce la STC 97/2002: «Ciertamente, el veto integra un rechazo frontal y global al proyecto o proposición remitidos por el Congreso, es decir, una enmienda a la totalidad». A favor de la restricción en la legitimación activa para formular propuestas de veto, exigiendo a tal efecto el apoyo de un número no excesivo, pero sí significativo de senadores, J. J. PÉREZ DOBÓN, «Las fases de comisión y Pleno», El procedimiento legislativo. V Jornadas de Derecho Parlamentario, Congreso de los Diputados, Madrid, 1997, pág. 480.

70 Las enmiendas pueden haber sido aceptadas sólo en parte, siendo necesario conocer si el grupo se da por satisfecho con ello o continúa postulando la aceptación en su integridad. 
que otras pueden haber perdido sentido en función de las modificaciones introducidas (por ejemplo, por haber desaparecido el artículo al que se referían) o de las transacciones o pactos efectuados.

También en la legitimación difieren los Reglamentos: mientras que el del Congreso atribuye la presentación de escritos de defensa de enmiendas y votos particulares a los grupos parlamentarios (lo que es coherente con la reserva de los debates plenarios para la defensa de las posiciones políticas, así como con la correlativa reserva a los grupos de la presentación de enmiendas a la totalidad), el Reglamento del Senado permite a los senadores (miembros de la Comisión o autores de enmiendas presentadas) la defensa de votos particulares ante el Pleno, con lo que se mantiene una postura más respetuosa con el papel de los parlamentarios individuales, eliminando el filtro ${ }^{71}$ que representa la firma del portavoz o, lo que es lo mismo, la asunción de las enmiendas por el grupo, que será en el Congreso el único que dispondrá de turno de defensa de enmiendas y votos particulares en el Pleno.

De esta forma, la defensa de las enmiendas al articulado se aproxima más a las enmiendas de totalidad ${ }^{72}$, no sólo por el tipo de debate que van a provocar, sino porque manifiestan una opción política diversa, no aceptada por la mayoría en la Comisión y que difícilmente será aceptada por el Pleno. Así, aunque la atribución a los grupos del mantenimiento de enmiendas y votos particulares para su defensa en el Pleno puede ser considerado negativo para las facultades de los parlamentarios individuales, resulta efectivo para que el debate se mantenga en términos de confrontación de posiciones políticas.

En el Senado, el artículo 117.1 y 2 RS permite formular y defender votos particulares a los miembros de la Comisión o a los senadores que hubieran defendido enmiendas no aceptadas, así como a cualquier senador (miembro de la Comisión, sustituto o enmendante, porque los demás no tendrían voz en la Comisión — 63 RS_-, imprescindible para poder hacer la manifestación necesaria) que haya expresado su deseo de convertir en enmienda el texto anterior del proyecto o proposición de ley, a los efectos del mantenimiento de un voto particular.

La consecuencia de la diferencia de legitimación entre los dos Reglamentos para la formulación de votos particulares es trascendente, al menos sobre el papel. El del Senado abre el debate legislativo en el Pleno a los senadores individuales. Sin embargo, como la disciplina de grupo es la misma en una y otra Cámara (tal vez más laxa en el Senado) y se supone que, al menos en los dos grupos grandes, que constituyen el noventa por ciento de la composición de la Cámara, la presentación de enmiendas individuales deberá contar con el beneplácito interno del grupo, el resultado ha sido que tanto la presentación de enmiendas como la de votos particulares por los senadores individuales se ha ido reduciendo (por supuesto, totalmente en el grupo de la mayoría) en número e importancia. Limitadas en un primer momento a las famosas enmiendas de campanario ( «sobre el campanario o la carretera de mi pueblo», que permiten al parlamentario exhibir su interés en la circunscripción) al proyecto de ley de Presupuestos Generales del Estado, o a aquellos ca-

71 Nada desdeñable, para PÉREZ DOBÓN, y que suscita no pocos interrogantes (ibidem, pág. 471). Para F. SANTAOLALLA (Derecho parlamentario español, cit., pág. 264), con la reserva de la presentación de votos particulares a los grupos se acentúa aún más la disciplina y el predominio de éstos.

72 C.G. ORTEGA, «Los parlamentarios y los grupos como sujetos del control parlamentario en el procedimiento legislativo», cit., pág. 762. 
sos en que se pretenden multiplicar las intervenciones de un mismo grupo parlamentario para enfatizar su posición sobre el proyecto o proposición de ley, a partir de la VI legislatura desaparecen también estas enmiendas de campanario de los miembros del principal grupo de la oposición.

\section{d) Intervención en los debates}

En el legislativo como en otros procedimientos, los grupos deciden quiénes intervienen como sus representantes en los debates, que se han convertido en debates reglados compuestos de turnos de portavoces, de forma que el parlamentario interviene en nombre de su grupo o no podrá intervenir ${ }^{73}$. Recordemos que la participación en el debate forma parte del núcleo de la función representativa parlamentaria, en los términos que vengan establecidos por los Reglamentos (STC 141/2007, FJ 4).

En el procedimiento legislativo, el debate plenario sobre el dictamen de la Comisión cumple una doble función en el procedimiento legislativo: la expresión pública de la posición de los grupos parlamentarios sobre el texto legislativo que se debate, y que la mayoría alcance su objetivo de que la voluntad política se convierta en norma ${ }^{74}$.

El debate actual sobre textos legislativos se caracteriza por: ser un debate tasado o reglado, previéndose exclusivamente turnos a favor y en contra de las enmiendas y fijación de posición de los otros grupos parlamentarios, conforme a la estructura general del debate establecida en el artículo $74 \mathrm{RC}^{75}$; el protagonismo absoluto de los grupos parlamentarios (cuyos portavoces son los únicos intervinientes), acentuado por la práctica de agrupación de la defensa de todas las enmiendas de cada grupo en un solo turno; y la publicidad inherente a las sesiones plenarias (público, medios de comunicación, retransmisión en directo del canal parlamentario) marca la orientación de las intervenciones hacia un último destinatario, que es la opinión pública.

73 Como se ha expuesto supra, sólo el artículo 84.1 del Reglamento del Senado declara que todo senador puede intervenir una vez que haya pedido y obtenido la palabra (formulado de forma negativa en el artículo 70.1 del Reglamento del Congreso), pero el sistema general de debate, compuesto de un turno a favor, otro en contra y fijación de posiciones por los grupos parlamentarios (art. 74 del Reglamento del Congreso) excluye la intervención de los parlamentarios individuales. Tan sólo en ocasiones, al amparo de los artículos 203.3 RC y 66.3 RS, se abre un turno de parlamentarios individuales en las sesiones informativas de las comisiones. Un raro ejemplo del uso de este turno, al parecer habitual en la IX legislatura en las sesiones de la Comisión Mixta para la Unión Europea, en Diario de Sesiones de las Cortes Generales, n 113, 13 de abril de 2010, pág.15.

74 C.G. Ortega Santiago, «Los parlamentarios y los grupos como sujetos del control parlamentario en el procedimiento legislativo», cit., pág. 768.

75 Dado el carácter tasado del debate, común a todos los procedimientos (74 RC), no tiene mucho sentido la previsión de cierre cuando un asunto es suficientemente debatido, contenida en el artículo 76 RC. El debate se cierra cuando se acaban los turnos reglamentarios, limitados incluso para las réplicas. Véase en T. Martines y otros (Diritto parlamentare, Maggioli, Rimini, 1992, págs. 346-347), los intentos de reforma reglamentaria en Italia dirigidos a reconducir el debate legislativo en Pleno (que en la reforma de 1971 se calificó de «discusión sobre las líneas generales»), desde la tradicional libre intervención de los diputados previa inscripción, hasta la limitación de la palabra a los relatores, el Gobierno, un diputado por grupo y los diputados que expresen posiciones disidentes respecto de su grupo, aunque con posibilidad de ampliación a otros intervinientes. Véase también al respecto S. Tosi, Derecho parlamentario, cit., págs. 216 y ss., así como M. L. Mazzoni Honorati, Lezioni di diritto parlamentari, $2^{\mathrm{a}}$ ed, Giapichelli, Turín, 1995, págs. 228 y ss. 
El Reglamento del Congreso no establece un orden concreto del debate del Pleno sobre el dictamen de una Comisión, a diferencia del Reglamento provisional, en el que se ordenaba aquél por artículos, votándose las enmiendas y el texto al final de la discusión de cada uno de ellos (99.2 y 3). Asimismo, el Reglamento vigente del Senado fija el artículo como base del debate (a su vez, dentro de cada uno, comenzando por los votos particulares que más se aparten del dictamen a juicio de la Presidencia de la Cámara, lo que nunca se ha aplicado por su complejidad, art. 123.1), sin perjuicio de prever el cierre del debate (126 RS).

El artículo 118.2 RC contempla con gran flexibilidad la ordenación de la deliberación en el Pleno sobre textos legislativos, que podrá ordenar la Presidencia de la Cámara, oídas la Mesa y la Junta de Portavoces, "por artículos o bien por materias, grupos de artículos o de enmiendas, cuando lo aconseje la complejidad del texto, la homogeneidad o interconexión de las pretensiones de las enmiendas o la mayor claridad en la confrontación política de las posiciones».

La amplitud de este artículo, como también de los artículos 124 y 126 del Reglamento del Senado ${ }^{76}$, ha permitido que bajo su vigencia haya evolucionado el debate legislativo en los Plenos de las Cámaras, desde los primeros tiempos en que se debatían las enmiendas y el texto del dictamen artículo por artículo, pasando después al debate agrupado por títulos de la ley (que se mantiene, aunque uniendo varios de ellos para su debate acumulado, en función de la materia y de los consiguientes intervinientes por cada grupo, en el debate anual del proyecto de ley de Presupuestos Generales del Estado y — cuando existía - del proyecto de ley de medidas que le acompañaba, así como en el debate en comisión de algún otro proyecto de envergadura, como las grandes leyes procesales o los códigos), para desembocar finalmente en una única discusión del conjunto de las enmiendas y el texto del dictamen, con una sola intervención por grupo parlamentario.

Podemos decir que esta reducción en los tiempos del debate plenario y la simplificación del mismo no ha redundado en su perjuicio, sino al contrario, porque permite que no constituya una repetición del celebrado en la Comisión y mantenga el significado político de expresión de posiciones sobre el texto que le da su sentido propio.

En todo caso, la ordenación del debate por criterio distinto del unitario se decide en la Junta de Portavoces, bien en su reunión inmediatamente anterior al inicio de la sesión plenaria correspondiente, bien en aquella en que se introduce el proyecto o proposición en el orden del día, viniendo determinada la decisión por la longitud o complejidad del proyecto o por la heterogeneidad de las materias que contiene, que haya hecho necesaria o conveniente la distribución del trabajo y en consecuencia de las intervenciones entre distintos portavoces, así como por la ordenación observada en el debate previo en la Comisión.

76 Aunque en este caso se consideró necesario ya en 1984 dictar una Norma supletoria para la ordenación del debate que permitiera la agrupación de votos particulares para su debate y votación conjunta, en concreto a causa del elevado número de enmiendas recibidas por el Proyecto de Ley Orgánica del Derecho a la Educación (LODE) (Norma supletoria de 14 de febrero de 1984, BOCG Senado n 66, de 28 de febrero). La impugnación de esta norma dio lugar al ATC 183/1984, que no entra en el fondo del asunto por considerar que la eventual lesión habría en su caso procedido de una norma de carácter general que no podía ser objeto de recurso de amparo. 
Incluso, aunque prevista en los Reglamentos, ha caído también en desuso la presentación del dictamen por un miembro de la Comisión en el Pleno —antes más frecuente en el Senado- porque, a no ser en los grandes proyectos consensuados, carece de sentido, salvo que se atribuya al presidente de la Comisión la tarea de enunciar una mera crónica de los trabajos realizados, fechas y reuniones. No otra cosa puede decir el representante de la Comisión, en un debate que se caracteriza por expresar posiciones políticas encontradas. Por eso, sólo cuando se desea dejar constancia de una tramitación particularmente laboriosa o en la que se han alcanzado importantes acuerdos, se hace uso de la posibilidad de presentación del dictamen que brinda el artículo 118.1 RC y $120.1 \mathrm{RS}^{77}$.

El orden de las intervenciones para el debate, sea unitario del dictamen o para cada bloque de debate (títulos o artículos, en su caso, según la ordenación realizada por la Junta de Portavoces), es el siguiente:

Intervienen los representantes de los grupos parlamentarios enmendantes para la defensa de todas sus enmiendas al texto del proyecto o proposición que se correspondan con la fracción del dictamen que se debate (que puede no coincidir en ubicación sistemática o en numeración con el original), por diez minutos cada uno, habitualmente en una única intervención de cada grupo para todas sus enmiendas presentadas al proyecto o proposición. El orden es inverso a la importancia numérica del grupo en la Cámara, sin más base reglamentaria que la previsión contenida en el artículo 75.4 RC de que los turnos generales de intervención se inicien por el Grupo $\mathrm{Mixto}^{78}$.

Este orden se invierte para el debate del proyecto de ley de Presupuestos Generales del Estado (como ocurre con algunos otros debates de gran trascendencia política), en cuyo caso las intervenciones son de mayor a menor, cerrando el debate el grupo del que procede el Gobierno.

A continuación de la intervención de cada grupo enmendante o de todos los enmendantes, cabe un turno en contra, por aplicación de los artículos $74.1 \mathrm{RC}$ y $87 \mathrm{RS}$.

Concluida la defensa de las enmiendas y, en su caso, los turnos en contra de aquélla, intervienen los grupos no enmendantes para fijar su posición sobre el dictamen, de menor a mayor. Del uso de este turno para la finalidad prevista depende que el debate concluya aquí. En otro caso, se solicitarán los turnos de réplica señalados, o bien turnos de alusiones al amparo de los artículos 71 RC y 88 RS, a través de los que muchas veces se canalizan lo que no son sino réplicas.

En todas estas intervenciones, los oradores suelen ser los encargados por cada grupo parlamentario del estudio y tramitación del texto legislativo correspondiente, que normalmente habrán actuado como ponentes y como portavoces de su grupo ante la Comisión y, por tanto, con carácter previo al Pleno han discutido, negociado y trabajado juntos, por lo que no son infrecuentes las manifestaciones de respeto —incluso de

77 Esta presencia de la Comisión durante la discusión por el Pleno, como señala L. VILLACORTA MANCEBO (Hacia el equilibrio de poderes: comisiones legislativas y robustecimiento de las Cortes, Universidad de Valladolid, Valladolid, 1989, pág. 360), es prácticamente insignificante si se compara con la situación alemana, francesa o italiana, en que el informe de la Comisión es presentado ante el Pleno por un relator, que no es necesariamente el que cumple las funciones de tal en el desarrollo de las deliberaciones de la Comisión.

78 El Reglamento del Senado (art. 86) prevé la intervención de los portavoces en orden inverso al número de componentes de los grupos parlamentarios con carácter general para los debates, tanto en el Pleno como en las comisiones. 
afecto- hacia los otros intervinientes, que trascienden a las diferencias políticas, así como las referencias al clima reinante en los debates previos y a la actitud, conciliadora o no, de los representantes del grupo mayoritario. Estas manifestaciones serán tanto más positivas cuanto mayor sea el número de enmiendas aceptadas a lo largo del procedimiento.

e) Participación en las votaciones

Tanto en Comisión como en Pleno, el criterio es acumular en una votación las enmiendas de cada grupo a cada bloque de debate, habitualmente la totalidad del texto, y votar seguidamente asimismo en su conjunto la parte o totalidad del dictamen debatido. Pero este criterio se matiza por la necesidad de adecuarse al diferente sentido de voto (sí, no o abstención) hacia las diferentes enmiendas o artículos cuya votación se pretende acumular, dando lugar a peticiones de votación separada, que los distintos grupos parlamentarios presentan respecto de las enmiendas de otros grupos (a las suyas propias votarán a favor) y de los artículos que integran el dictamen ${ }^{79}$. La combinación de las peticiones de votaciones separadas dispares da lugar en ocasiones a más de doscientas votaciones (que exceden de una hora de duración, por procedimiento electrónico, en el Pleno) respecto de un proyecto o proposición. Si se votara enmienda por enmienda y artículo por artículo del dictamen, el número de votaciones, en función de los proyectos, podría elevarse considerablemente ${ }^{80}$.

Las enmiendas transaccionales son objeto de votación (habitualmente separada) en el lugar que ocupaba la enmienda retirada o al final, y las correcciones técnicas junto con la parte del dictamen a que afecten.

De todo lo expuesto puede parecer (con cierto fundamento) que las votaciones de textos legislativos constituyen un galimatías sólo comprensible para iniciados, a ser posible disponiendo del guión que preparan — sobre las peticiones de votación separada realizada por los diferentes grupos parlamentarios - los letrados que atienden a la sesión de Comisión o plenaria, bajo la dirección del Secretario General. Este guión se distribuye a los portavoces o secretarios técnicos de los grupos parlamentarios (o a los portavoces en la Comisión), encargados de indicar a sus miembros el sentido del voto alzando la mano con uno, dos o tres dedos levantados. La disciplina de los grupos hace el resto, lo que motiva que si el whip se equivoca lo harán también sus correligionarios, que suelen estar ajenos al objeto de su voto. En consecuencia, puede afirmarse que sólo los citados whips y los servicios jurídicos saben en concreto lo que se está votando y detectan cuándo se produce algún error sobre los propósitos iniciales o alguna desviación

79 La petición de votaciones separadas del dictamen por artículos o grupos de artículos aparece ya en algunos Reglamentos de Parlamentos autonómicos, más modernos que los del Congreso y el Senado, y que recogen por tanto la experiencia de funcionamiento (Andalucía, Madrid).

80 La petición de votaciones separadas puede utilizarse como elemento de obstrucción parlamentaria, para alargar la tramitación de un texto legislativo, como símbolo de protesta, por ejemplo, por la actitud intransigente de la mayoría. Frente a ello, y en aras de la economía procesal, el artículo 120.4 del Reglamento del Parlamento de Andalucía de 2005 establece que la votación desagregada de una enmienda o grupo de enmiendas de un grupo parlamentario sólo se produce cuando «de la intervención de los distitntos portavoces (se) dedujera la voluntad mayoritaria de la Cámara favorable a su aprobación». 
o sorpresa sobre los resultados previsibles. Dicho de otra manera, los parlamentarios participan en las votaciones siguiendo «a ciegas» las indicaciones de los dirigentes del grupo.

La votación en el Pleno de textos legislativos se realiza habitualmente por procedimiento electrónico, conociéndose el sentido del voto de los diputados (pues están prohibidas las votaciones secretas en los procedimientos legislativos, 85.1 $\mathrm{RC}^{81}$ ) por el color con que aparecen reflejados sus escaños en el marcador situado en el salón de sesiones, a ambos lados de la Presidencia ${ }^{82}$. Una copia del listado de votaciones con el sentido del voto de los diputados se hace llegar a los grupos parlamentarios y se facilita a los representantes de los medios de comunicación que lo soliciten.

En los procedimientos legislativos, no cabe en el Congreso la votación secreta, prohibida por el artículo $85.1 \mathrm{RC},{ }^{83}$ con lo que se da plasmación normativa a la consustancialidad de la publicidad con el procedimiento legislativo frente a otros procedimientos de producción normativa ${ }^{84}$. La prohibición de votación secreta refuerza la disciplina del grupo parlamentario, que aplica sanciones pecuniarias a la no asistencia (a veces deliberada, porque el representante no quiere oponerse públicamente a la posición de su grupo) y a la votación, intencionada o por error, en contra de sus indicaciones ${ }^{85}$.

81 Prohibición consecuencia, señala P. BIGLINO CAMPOS («Procedimiento legislativo», en Enciclopedia jurídica básica, vol. III, Civitas, Madrid, 1995, pág. 5186), del carácter representativo inherente a la institución parlamentaria: dado que el ciudadano no participa directamente en la toma de decisiones, tiene que tener al menos garantizada la posibilidad de conocer el sentido de lo actuado por el representante.

$82 \mathrm{El}$ artículo $84.2^{\circ} \mathrm{RC}$ prescribe que la votación ordinaria por procedimiento electrónico acredite el sentido del voto de cada diputado y los resultados totales de cada votación.

83 Siguiendo así un principio continuamente mantenido en nuestra tradición parlamentaria, como recuerda F. RUBIO LLORENTE («El procedimiento legislativo en España: el lugar de la ley entre las fuentes del Derecho», cit., pág. 95). Puede verse la denegación de una solicitud de votación secreta de unas enmiendas al Proyecto de ley de Presupuestos Generales del Estado en el Diario de sesiones del Congreso n ${ }^{\circ} 128$, de 15 de noviembre de 2005, pág. 6476. Ejemplos de votaciones secretas por papeletas en materia no legislativa en el Pleno del Congreso, durante la vigencia del presente Reglamento, son las celebradas el 15 de octubre de 1995 (Diario de sesiones $\mathrm{n}^{\circ} 175$, pág. 9331) sobre la creación de una Comisión de investigación sobre los GAL, y el 4 de marzo de 2003, de dos proposiciones no de ley sobre la crisis de Irak (Diario de sesiones no 230 , pág. 11730); de votación secreta por procedimiento electrónico, la celebrada el 29 de noviembre de 2005 (Diario de sesiones $n^{\circ} 133$, pág. 6787) sobre una moción del Grupo parlamentario IV-IU-ICV, relativa a la financiación de la Iglesia católica y demás confesiones religiosas.

84 Véase I. DE OTTO, Derecho Constitucional. Sistema de fuentes, cit., pág. 106.

85 El diario El País de 30 de junio de 2010 recoge, citando como fuente a los propios grupos parlamentarios, un listado de los diputados sancionados en las dos últimas legislaturas por romper la disciplina de voto, en el que se encuentran diecisiete diputados socialistas encabezados por Álvaro Cuesta (apoyo a una enmienda de Izquierda Unida a los Presupuestos Generales del Estado que pedía la supresión de la asignación a la Iglesia) y los diputados Barrio de Penagos (PSOE, por el apoyo a una moción de IU contra el fichaje de David Taguas por la patronal de las constructoras; el diputado alegó que su voto obedeció a un error), Arsenio Pacheco y Alberto Garre (PP, por el voto en contra de la toma en consideración de la reforma del Estatuto de Castilla-La Mancha, que incluía un artículo previendo el final del trasvase Tajo-Segura) y Antonio Gutiérrez (PSOE, en relación con la votación sobre devolución de patrimonio a UGT y — no constando la sanción - por la abstención en la convalidación del Decreto-ley de reforma laboral). La diputada Celia Villalobos (PP) fue sancionada, en la VIII Legislatura, por su voto a favor de la Ley que introducía el matrimonio homosexual. No así, según la fuente citada, en la IX Legislatura, cuando rompió la disciplina de voto respecto de la ley que reforma los supuestos de despenalización del aborto y alegó que se trataba de un error. 
Tal vez no sea superfluo recordar aquí una vez más que quien ejerce su derecho al voto es el parlamentario, facultad personal e indelegable y no sujeta a mandato imperativo conforme a los artículos 79.3 y 67.2 de la Constitución, ${ }^{86}$ y que el derecho al voto forma parte del núcleo de la función representativa parlamentaria, como ha expresado el Tribunal Constitucional (STC 361/2006, FJ 3$)^{87}$.

\section{Integración de las ponencias y Comisiones}

Además de estas intervenciones en el procedimiento legislativo, afecta al mismo, como a otros procedimientos, la posición de los grupos parlamentarios en distintos aspectos de la organización y el funcionamiento de las Cámaras. En particular, ha de tenerse en cuenta que los grupos parlamentarios designan a los miembros de las comisiones y ponencias que tramitan los proyectos legislativos, de una parte, y que determinadas decisiones se adoptan en algunos órganos parlamentarios mediante voto ponderado.

$¿$ Cabe pensar que los dirigentes de los grupos respetan las preferencias y peticiones de los parlamentarios individuales para actuar como ponentes respecto de un texto concreto o para formar parte de una Comisión?

En lo que se refiere a las ponencias, si su propia composición, tal como aparece en las distintas Resoluciones referida a los miembros por cada grupo parlamentario, revela el carácter de protagonistas de los grupos en las ponencias, la forma de su designación lo confirma: por encima del parlamentario individual que pueda estar interesado o especializado en la materia objeto del texto legislativo, pero por encima sobre todo de la libertad de decisión de las comisiones, que son las facultadas — según los artículos 113.1 RC y 65 RS - para el nombramiento de los ponentes, la designación de las personas concretas corresponde a los grupos, limitándose la Comisión a ratificar sus propuestas.

¿Con qué criterios designan los grupos parlamentarios a los ponentes? Cabe pensar en dos: competencia sobre la materia y conexión con la jerarquía del grupo, para que mantenga la línea que se corresponde con la posición del grupo parlamentario. No sería aventurado afirmar que el segundo criterio prevalece sobre el primero, si bien la figura de los portavoces y portavoces adjuntos en las comisiones (o lo que los grupos denominan «coordinadores de área») garantiza una cierta especialización, aunque en ocasiones varían de cometido de una legislatura a otra.

Lo hasta aquí señalado es aplicable a los dos grupos de mayor tamaño (PSOE y PP), que cuentan siempre con más de cien diputados cada uno; incluso a los grupos medianos,

86 Por más que el Tribunal Constitucional haya introducido algún elemento de perplejidad al reconocer la legitimación del grupo parlamentario y la lesión de sus derechos en la Sentencia 361/2006, sobre votación de la Ley de Presupuestos en el Parlamento Vasco. Véase P. GARCÍA-ESCUDERO MÁRQUEZ, «¿Es posible repetir las votaciones parlamentarias? ¿Vota el diputado o el Grupo parlamentario?», TRC, n 20, 2007, págs. 609 y ss., y J. Ma. MORALES ARROYO, El conflicto parlamentario ante el Tribunal Constitucional, CEPC, Madrid, 2008, págs. 93-94.

87 «No ha habido, hasta ahora, un pronunciamiento claro al respecto, pero dicha pertenencia [al ius in officium\} se deriva de la naturaleza misma de las cosas. Uno de los principales derechos/deberes de aquéllos [los parlamentarios] es la participación en las tareas de las Cámaras, y la forma más habitual de concretar la misma es el ejercicio de su derecho al voto, ejercicio con el que manifiestan su postura en los acuerdos de las Asambleas». 
de más de quince diputados. Pero en los de menor número de miembros, por debajo de diez diputados ${ }^{88}$ la especialización abarca un amplio ámbito, porque cada miembro tiene que multiplicarse para atender a las comisiones legislativas (diecinueve en el Congreso y veintiuno en el Senado en 2011) y de otro tipo que le toquen en suerte, incluidas las ponencias que hayan de informar los distintos proyectos y proposiciones de ley de tramitación simultánea. De ahí que no sea de extrañar la ausencia de los representantes de estos grupos reducidos en reuniones de ponencias y comisiones, acudiendo, en su caso, sólo a las votaciones correspondientes al dictamen. Todo ello, con las excepciones que toda generalización comporta, que dependen, además de la personalidad concreta del diputado, de la capacidad de influencia de su grupo (derivada de su peso político en la legislatura), de la necesidad de formar mayorías o de la relevancia general o para el grupo que presente el proyecto o proposición de ley.

En cuanto a las Comisiones, nuestros Reglamentos atribuyen directamente a los grupos parlamentarios la designación de sus miembros en el número que, respecto de cada uno, haya fijado la Mesa, oída la Junta de Portavoces, y en proporción a la importancia numérica de aquéllos en la Cámara (40.1 RC, 51 RS).

Esta designación se realiza mediante escrito dirigido a la Mesa, la cual simplemente acepta la declaración de voluntad emitida, siempre que se atenga al número de miembros que al grupo corresponde en la comisión.

Desde el momento que se atribuye la designación de los miembros de las comisiones a los grupos parlamentarios sin otra limitación que su número, queda en sus manos la determinación de los criterios a aplicar para realizar la distribución de los puestos en las comisiones. Desde siempre se ha pensado que el sistema de comisiones permanentes permite, a diferencia de las secciones (formadas por el azar o la división alfabética), la especialización de sus componentes, bien al ser designados miembros los mejores conocedores de la materia objeto de la comisión, bien porque fueran adquiriendo tal conocimiento por su permanencia en la misma ${ }^{89}$. Sin embargo, aunque no cabe descartar que los grupos parlamentarios tengan en cuenta estas cualificaciones (como también consta que los parlamentarios expresan a la dirección del grupo sus preferencias al comienzo de la legislatura ${ }^{90}$ ), lo cierto es que se combinan con consideraciones de orden político, que suelen acabar predominando en la designación, siendo prueba de ello la relativamente alta movilidad de una legislatura a otra entre los miembros de las comisiones de un mismo

88 En la VIII y en la IX legislaturas (iniciadas en 2004 y 2008, respectivamente), de los otros grupos constituidos en el Congreso, uno cuenta con diez diputados (Catalán-CiU) y los restantes con menos de diez.

89 P. Pactet constataba en la III y la IV República francesas que, salvo excepciones, los diputados no son adscritos a las comisiones por ser especialistas sino para llegar a serlo ( Les Commissions parlementaires», Revue de Droit Public et de la Science Politique en France et à l'étranger, 1954, págs. 128-129.

90 Criterio de elección personal del parlamentario por razón de su experiencia, prestigio o antigüedad, predominante en el siglo XIX, como recuerda J.L. PANIAGUA SOTO ( El sistema de comisiones en el Parlamento español», RFDUC, nº 10, 1986, pág. 119), en combinación unas veces con la voluntad del Presidente de la Cámara o de la sección, que era el órgano de elección. Hoy, dice este autor, la designación por los grupos deja abierto el camino para que el partido o grupo encumbre a un representante, dándole puestos clave de responsabilidad y de presencia pública o, por el contrario, le condene a funciones administrativas en lugares poco deseados (que también los hay). Así, el grupo utiliza su capacidad decisional para disciplinar al parlamentario, lo que puede contribuir a un buen funcionamiento de la Cámara o a vicios que dejarán sentir sus aspectos más negativos, eso sí, justificados en aras de la homogeneidad, la cohesión interna, la estabilidad interna, etc. (pág. 120). 
grupo parlamentario, incluidos los portavoces o coordinadores de área ${ }^{91}$. Ello es indicio de que la confianza política o la conexión con la jerarquía del grupo prima sobre otros criterios más técnicos, y causa de que los parlamentarios — por fuerza — se vayan especializando sucesivamente en temas distintos.

En ocasiones, la especialización proviene de haber desempeñado tareas en el Gobierno o en una Administración autonómica, dependiendo de cuyo rango podrá aspirarse a una presidencia o una portavocía de comisión en el Congreso. A la inversa, de éstas últimasdesempeñadas en la oposición — puede pasarse con relativa facilidad a un puesto de alto nivel en el Ejecutivo (Secretario de Estado o incluso Ministro) cuando el partido gana las elecciones. El inicio de las legislaturas ha mostrado muchos ejemplos, que también tienen lugar con ocasión de elecciones autonómicas en el curso de la legislatura.

En todo caso, se requerirá un mínimo de conocimiento de la materia objeto de la comisión para poder intervenir ante ella o para, como indica Arce Janáriz ${ }^{92}$, asimilar las directrices del grupo y no separarse, por descuido o desconocimiento, de sus prescripciones. Es posible que, en la falta de conocimientos previos que cubran todo el ámbito de acción estatal entre los integrantes de las listas electorales y en la posterior adjudicación de miembros a las comisiones, radique buena parte de las razones de la insistencia con que la oposición, cualquiera que sea, suele reclamar la incorporación de expertos a las comisiones, bien por vía de asesoramiento o contratación, bien por vía de audiencia.

Con posterioridad a esta designación inicial, los grupos, como titulares de los puestos en las comisiones ${ }^{93}$, pueden sustituir libremente a sus miembros. Esta sustitución definitiva, distinta de la coyuntural a que aludiremos a continuación, debe ser notificada por el portavoz por escrito al Presidente de la Cámara (40.2 RC, 62.2 RS) y se publica en el Boletín Oficial de las Cortes Generales como alta y baja producidas en la comisión. El

91 P. OÑATE («La organización del Congreso de los diputados», en El Congreso de los Diputados en España: funciones y rendimiento, A. MARTÍNEZ, ed., Tecnos, Madrid, 2000, págs. 89-90) afirma que el índice de renovación de los miembros titulares de las comisiones permanentes legislativas de una legislatura a otra es considerablemente más alto que el ya elevado que se registra en el conjunto de la Cámara (68 por ciento frente a 45,5 por ciento, entre la V y la VI legislatura). Bien es verdad, apuntamos nosotros, que se trata de un cambio de legislatura con distinta mayoría parlamentaria, con la consiguiente variación en la composición de las comisiones, pero aún así el porcentaje de renovación es muy alto, llegando al 80 por ciento en tres comisiones. En el mismo sentido, afirma J. CAPÓ GIOL (La legislación estatal en la España democrática. Una aproximación politológica, CEC, Madrid, 1990, pág. 118) que son muchos los indicadores que muestran la profunda inestabilidad de las comisiones permanentes legislativas; en realidad, el atributo de permanencia sólo tiene un sentido formal, referido al propio órgano, pero no a su composición personal, por lo que se permite la pequeña broma de titular el capítulo a ellas dedicado «Las comisiones legislativas no permanentes». El autor realiza un detenido estudio (págs. 118 y ss.) de la variación de los miembros en las comisiones legislativas permanentes en las tres primeras legislaturas, revelando el resultado una escasa continuidad o, lo que es lo mismo, la no formación de unos núcleos que se mantengan por criterios de antigüedad (la seniority norteamericana) en las mismas comisiones (pág. 121). Véase también, sobre «el trasiego de los miembros de las comisiones en el Congreso», un análisis más reciente basado en entrevistas a los parlamentarios, en L. M. MAUER, El poder del Parlamento. Congreso y políticas públicas en España, CEPC, 2008, págs. 113 y ss.

92 A. ARCE JANÁRIZ, «Creación, composición y órganos directivos de las comisiones parlamentarias», en DA SILVA OCHOA, J. C. (coord.), Las Comisiones parlamentarias, Parlamento Vasco, Vitoria-Gasteiz, 1994, pág. 300 .

93 F. SANTAOLALLA LÓPEZ, Derecho parlamentario español, 1ª ed., Editora Nacional, Madrid, 1984, pág. 140. 
Reglamento del Senado añade cautelarmente - aunque es obvio- que el sustituto no ocupará el cargo que, en su caso, ostentase el senador sustituido en la comisión, es decir, que el nuevo miembro no pasa automáticamente a ser presidente, vicepresidente o secretario de la comisión, cargo para el que fue elegido el sustituido y que requerirá nueva elección de quien vaya a ocupar su puesto. En todo caso, las sustituciones producen, como se ha señalado, cierta inestabilidad en la composición de las comisiones ${ }^{94}$.

Además de poder ser dados de baja y nombrados otros, los miembros de la comisión pueden ser sustituidos por otros miembros de la Cámara para alguna sesión («en cada sesión», $62 \mathrm{RS}$ ) o incluso parte de la misma («un determinado asunto, debate o sesión», dice el artículo 40.2 RC), previa comunicación verbal o escrita (por escrito en el Senado) al presidente de la comisión. El Reglamento del Congreso, más flexible con las sustituciones porque admite que tengan carácter meramente eventual, en cuyo caso el presidente admitirá como miembro de la comisión indistintamente al sustituto o al sustituido ${ }^{95}$ atribuye la facultad de sustitución a los grupos parlamentarios. El Reglamento del Senado, además de establecer que las sustituciones se hagan al inicio de la sesión, reconoce como autores del escrito tanto al miembro titular como al portavoz del grupo.

Las causas de este sistema tan permisivo han de buscarse en el deseo de funcionalidad de las comisiones, de manera que la ausencia de diputados, justificada o no, no impida su reunión. No obstante, la doctrina ${ }^{96}$ critica en general (y la realidad es ciertamente criticable) la flexibilidad del sistema de sustituciones, cuyo uso y abuso acaba con toda posible especialización de los miembros de la comisión. La alternativa a la sustitución libre sería el nombramiento de un suplente a la par que el miembro titular, como en Alemania ${ }^{97}$, o la presentación por el grupo de una lista de suplentes para cada comisión al inicio de la legislatura, como en Dinamarca ${ }^{98}$, aunque tampoco se confía en que ésta sea la panacea, porque su eficacia dependería de la diligencia del suplente para estar siempre preparado y el grado de comunicación entre titular y suplente ${ }^{99}$.

La flexibilidad descrita del régimen de suplencias conduce a que, ahora sí, se reclame la presencia de parlamentarios individuales para cubrir el cupo de miembros del grupo en la Comisión, aunque sea a los solos efectos de participar en las votaciones ${ }^{100}$.

94 Y no actúa en favor de la especialización de sus miembros, como señala B. VILA RAMOS (Los sistemas de comisiones parlamentarias, CEPC, Madrid, 2004, págs. 328-329).

95 Lo que lleva la inseguridad jurídica hasta el extremo: puede ocurrir que estén presentes ambos diputados, sustituido y sustituto, interviniendo alternativamente uno u otro.

96 F. RUBIO LLORENTE, La forma del poder. Estudios sobre la Constitución, CEC, Madrid, 1993, pág. 206; F. SANTAOLALLA LÓPEZ, Derecho parlamentario español, cit., págs. 140-141; L. VILLACORTA MANCEBO, Hacia el equilibrio de poderes: comisiones legislativas y robustecimiento de las Cortes, cit., pág. 246; A. ARCE JANÁRIZ, «Creación, composición y órganos directivos de las comisiones parlamentarias», cit., pág. 308.

97 F. CAAMAÑO DOMÍNGUEZ, El mandato parlamentario, cit., pág. 225.

98 E. VÍRGALA FORURIA, «Las comisiones y ponencias: con especial referencia al Reglamento del Parlamento Vasco», en Parlamento y Derecho, Parlamento Vasco, Vitoria-Gasteiz, 1991, págs. 275-276.

99 A. ARCE JANÁRIZ, «Creación, composición y órganos directivos de las comisiones parlamentarias», cit., pág. 309.

100 Son de aplicación a las comisiones las reglas generales sobre quórum de asistencia: inician sus sesiones cualquiera que sea el número de parlamentarios presentes (82 RS), pero se requiere que asista la mayoría de sus miembros para poder adoptar acuerdos (78.1 RC, 93.1 RS). En el Congreso, si llegado el momento de la votación o celebrada ésta resultase que no existe quórum, se pospondrá la votación por el plazo máximo de dos ho- 


\section{El voto ponderado}

Es precisamente en relación con la prohibición constitucional del mandato imperativo, así como con la proclamación del voto como personal e indelegable en el artículo 79.3, como se plantea la posible inconstitucionalidad del voto ponderado, que el Reglamento del Congreso reconoce como forma de adopción de acuerdos en la Junta de Portavoces (art. 39.4), el Reglamento del Senado en la Comisión de Nombramientos (art. 185.2) y ambos recogen como forma de resolver los empates en comisión (88.2 RC, tras la reforma de 23 de septiembre de 1993; 100.4 RS, tras la reforma de 24 de octubre de 1995).

En el Congreso de los Diputados, esta forma de voto se establece para la Comisión Consultiva de Nombramientos en la Resolución de la Presidencia que la crea y regula, de 25 de mayo de 2000 (apartado tercero 2), y en el Senado para las ponencias por la Norma interpretativa de 18 de noviembre de 1997, lo que venía aplicándose de forma inveterada en ambas Cámaras, como por otra parte también, sin norma que lo ampare, en aquellas comisiones cuya composición no refleja la del Pleno (Comisiones de Reglamento, Peticiones y Estatuto del Diputado, en el Congreso).

Creemos que puede mantenerse la constitucionalidad de la adopción de decisiones de esta forma en la Junta de Portavoces, e incluso su coherencia lógica, dado el carácter que presenta de órgano de representación y hasta de confrontación política, que, por otra parte, no interviene directamente en el ejercicio de las funciones de las Cámaras. Sí indirectamente, pues tales decisiones afectan a los distintos procedimientos: en el legislativo, señaladamente, a la inclusión de los textos legislativos en el orden del día del Pleno en sus sucesivas lecturas; en los distintos procedimientos de control (preguntas, interpelaciones...), además de las competencias de la Junta de Portavoces en el orden del día (decisorias en el Congreso, art. 67.1 RC; consultivas en el Senado, art. 71.1 RS), el sistema de cupos acordado por la respectiva Junta hace a los grupos parlamentarios dueños de los procedimientos.

Aún así, puede entenderse que estas intervenciones, siempre que no vulneren flagrantemente los derechos de los parlamentarios ex artículo 23, entran dentro de la dinámica mayorías/minorías.

Pero no cabe adoptar la misma actitud respecto de la aplicación del voto ponderado en las comisiones. Éstas constituyen órganos de trabajo, no de gobierno, de la Cámara, que preparan el trabajo del Pleno o incluso lo sustituyen, de ahí su composición proporcional a la de aquél. Sabemos que las comisiones pueden aprobar definitivamente leyes en caso de delegación, en virtud del artículo 75.2 de la Constitución, y que no cabe la delegación de voto por los parlamentarios en el ejercicio de sus funciones (art. $79.3 \mathrm{CE}$ ). De ahí que sólo con dificultades quepa aceptar la ponderación de voto en co-

ras. Si transcurrido este plazo tampoco pudiera celebrarse válidamente aquélla, el asunto sería sometido a decisión de la comisión en la siguiente sesión (68.2 RC). En el Senado, se presume la presencia del número legal necesario para adoptar acuerdos. No obstante, será necesaria su comprobación cuando antes de iniciarse una votación lo requiera un grupo parlamentario o cinco senadores. Si se comprueba la falta de quórum para adoptar acuerdos, el presidente de la comisión podrá aplazar la votación hasta el momento que señale (93.2 y 4 RS). 
misión, atendiendo a que las previsiones reglamentarias lo aplican sólo como técnica, no ya para dirimir un empate, sino para entender que éste no se produce ${ }^{101}$.

No ocurre así, en cambio, en las ponencias, órgano — asimismo de trabajo — interno de la comisión, cuya función es presentar un informe sobre las enmiendas, que constituye una propuesta para aquélla, la cual debate y vota las enmiendas y el texto propuesto. Sin perjuicio de que, en la práctica, la labor previa de la ponencia es decisiva para la posterior actuación de la comisión, por cuanto su informe constituye la base de discusión en ella, el valor jurídico del informe de la ponencia es de mera propuesta, como también propone la aceptación o rechazo de las enmiendas presentadas. Este valor no decisorio, sino consultivo, permite admitir el voto ponderado en las ponencias, justificado por otra parte, como señala el Preámbulo de la Norma interpretativa de la Presidencia del Senado de 18 de noviembre de 1997, en la conveniencia de no constituir ponencias de composición muy numerosa, que permitiera atender al criterio proporcional, y en que su naturaleza de órgano de trabajo y el principio de economía procedimental aconsejan que las decisiones a adoptar en su seno sean previsiblemente concordantes con las que se tomen en otras instancias de la Cámara, en primer lugar en las propias comisiones.

\section{CONCLUSIÓN}

De lo expuesto sobre la intervención de los parlamentarios en el procedimiento legislativo resulta como conclusión que, además de los preceptos reglamentarios restrictivos de la posición de aquellos, la práctica y los precedentes han acentuado el protagonismo absoluto de los grupos. Así, los diputados y senadores nunca presentan proposiciones de ley, siendo siempre los grupos sus autores; y, pese a que los Reglamentos admiten la presentación de enmiendas individuales, los grupos monopolizan de hecho el ejercicio del derecho de enmienda, agrupándose su defensa por grupos parlamentarios tanto en la Comisión como en el Pleno. La participación, al menos en lo que a los dos grupos mayoritarios se refiere — pues el pequeño tamaño de los restantes grupos permite, e incluso exige, que todos sus miembros desarrollen una amplia labor parlamentaria interviniendo en los distintos procedimientos- depende de la voluntad de los dirigentes del grupo y puede llegar a reducirse al «aparato» del mismo, formado por sus portavoces en Comisión y expertos en determinadas materias.

La explicación que se quiere dar a esta posición predominante de los grupos parlamentarios es la misma que se aplica a los partidos en la vida política: constituyen la proyección de las opciones políticas legitimadas a través del sufragio, y, por tanto, el papel privilegiado que reciben en la reglamentación de todos los procedimientos parlamentarios tiene su razón de ser no sólo en la funcionalidad de las Cámaras (que tampoco podrían funcionar ágilmente sin intentar agrupar de alguna forma las trescientas cincuenta o doscientas sesenta y cuatro voces y voluntades), sino en que los

101 Con anterioridad a la reforma de 1993, el artículo 88.3 del Reglamento del Congreso, hoy derogado, excluía, con mayor corrección, del recurso al voto ponderado en caso de empate los procedimientos legislativos en los que la Comisión actuara con competencia plena, así como las mociones y proposiciones no de ley en comisión. Tal vez la eliminación de este apartado se debió a la previsión (excesiva) que contenía de recurrir al Pleno para dirimir el empate tras las votaciones previstas en el apartado 1 de dicho artículo. 
grupos manifiestan institucionalmente el pluralismo político propio de las sociedades complejas ${ }^{102}$.

¿Qué le queda pues al parlamentario individual? ¿Presentar enmiendas, que hemos visto no presenta en la realidad? ¿Solicitar ser ponente de un texto legislativo o miembro de una Comisión? ¿Promover una iniciativa — proposición de ley o enmienda- de su grupo parlamentario?

En la actual situación de predominio del grupo sobre el parlamentario que parece constituir el signo de los tiempos, debemos abogar por la no suplantación absoluta de los representantes por los grupos que ellos crean ${ }^{103}$. Llevado al extremo, podrían reducirse las Cámaras a una Junta de Portavoces con voto ponderado en función de los resultados electorales. Sabemos que la disciplina de voto coarta realmente la posibilidad de libre ejercicio de su función por los parlamentarios individuales, pero al menos debe garantizárseles la participación en los procedimientos con un mínimo de autonomía. Si la relación representanteelector se ha visto sustituida por la relación representante-partido-elector, incluso fraccionada en dos (representante-partido, partido-elector) o reducida a la relación partido-elector ${ }^{104}$, ello no debe propiciar que el llamado mandato de partido viole la prohibición de mandato imperativo proclamada por el artículo 67.2 de la Constitución ${ }^{105}$.

Biglino entiende también que el marcado protagonismo de los grupos en las asambleas produce una cierta fractura entre la teoría de la representación mantenida por el Tribunal Constitucional y el funcionamiento del Parlamento: mientras la titularidad del mandato corresponde al parlamentario individual, porque así lo ha querido el cuerpo electoral, el ejercicio del mandato en los procedimientos parlamentarios corresponde casi en exclusiva al grupo en el que se integran ${ }^{106}$. En el mismo sentido, Rubio Llorente afirma que, como consecuencia del cambio en la naturaleza y en la estructura interna de los partidos, los parlamentarios no actúan ya como voluntades libres no sometidas a mandato imperativo alguno; actúan de hecho simplemente como portavoces de su propio partido,

102 Incluso, dice M. ${ }^{a}$ L. BALAGUER CALLEJÓN ( «La relación entre los grupos parlamentarios y los partidos políticos en el ordenamiento jurídico-constitucional español», Corts. Anuario de Derecho Parlamentario, $\mathrm{n}^{\circ}$ 10, 2001, pág. 43), el grupo parlamentario se convierte en el eje en torno al cual se produce la tensión política de los partidos, si tenemos en cuenta que el grupo parlamentario es aquella institución donde se desenvuelve la más importante acción política, tanto en el intento de desgaste de la oposición como en la justificación y defensa del Gobierno.

103 En el mismo sentido, C. PAUNER CHULVI ( El estatuto de los parlamentarios en un contexto multinivel: las relaciones entre parlamentarios, grupos y partidos», cit., pág. 254), «siendo posible dar un giro a la sobredimensión que han adquirido los grupos en las funciones parlamentarias volviendo a la figura del representante y, en defensa de su posición, aprovechar todas las potencialidades individuales manteniendo, en todo caso, la protección constitucional como derecho fundamental y la garantía que ello conlleva frente a la voracidad de los partidos políticos».

104 Véase A. GARRORENA MORALES, «Apuntes para una revisión crítica de la teoría de la representación», en El Parlamento y sus transformaciones actuales, A. GARRORENA MORALES (Ed.), Tecnos, Madrid, 1988 , págs. 46 y ss.

105 Recuérdese la doctrina del Tribunal Constitucional, iniciada con las sentencias 5/1983, de 4 de febrero y 10/1983, de 21 de febrero, a favor del mandato representativo y, en suma, de la relación elector-representante.

106 P. BIGLINO CAMPOS, «Veinticinco años de procedimiento legislativo», cit., pág. 455. No obstante, esta autora manifiesta que no está claro que la posición de los parlamentarios en la actualidad deba ser modificada, dado el papel que la Constitución española atribuye a los partidos políticos en el artículo 6 y a los grupos parlamentarios en relación con la composición de la Diputación Permanente o la investidura. 
como sometidos a la disciplina del grupo o de la fracción y, eventualmente, de los órganos directores del partido que actúan fuera del ámbito parlamentario ${ }^{107}$.

Frente a esta situación, cabe plantearse no obstante una reforma reglamentaria de los procedimientos que potencie la participación del diputado individual sin privar del protagonismo a los grupos parlamentarios. En este sentido, hemos reclamado la supresión de la exigencia reglamentaria de la firma del portavoz para las enmiendas de parlamentarios individuales, pero al mismo tiempo reconocemos que el papel fundamental en el debate sobre posiciones políticas en el Pleno debe reservarse a los grupos parlamentarios. Por tanto, parece que la Comisión debería ser el foro donde se escuchara la voz de los parlamentarios para hacer patente su participación en el procedimiento legislativo.

No es fácil hallar un equilibrio entre la primacía del grupo y la participación individual de los miembros de las Cámaras ${ }^{108}$, que se nos antojaba la cuadratura del círculo. En todo caso, el objetivo ha de ser alcanzar la integración de los parlamentarios en la formación de la ley, de manera que ésta se aproxime lo más posible a la opinión mayoritaria de los ciudadanos expresada en las urnas ${ }^{109}$, y conseguir que su intervención no se limite a oprimir un botón en el sentido que le impone su grupo parlamentario.

$* * *$

TITLE: The individual Member in a group centred Parliament (participation in the legislative function)

ABSTRACT: This article examines how the Constitution and the Rulings of the Constitutional Court establish a concept of an individual Member or Parliament as the representative empowered with a parliamentary mandate as well as entitled to exercise the constitutional powers of the Chambers. This concept is then conforted to the rulers of the Standing Orders and the day-to-day parliamentary pratice in order to ascertain how these modify the Member's scope of action and what parliamentary activities have in effect been «taken over» by Parliamentary Groups, wich are perceived as the central characters of the political game and the real initiators of almost all parliamentary proceedings in the Chambers.

RESUMEN: Se examina la concepción del parlamentario individual (supuesto autor, todavía titular del mandato representativo, del ejercicio de las funciones constitucionales de las Cámaras) que se obtiene de la Constitución y la jurisprudencia constitucional y compararla con la normativa contenida en los Reglamentos parlamentarios y con su aplicación práctica, para comprobar cuál es el ámbito de actuación que conserva aquél y cuál ha sido "usurpado» por los grupos parlamentarios, protagonistas del juego político y de la inmensa mayoría de las iniciativas e intervenciones en el seno de las Cámaras.

KeY Words: Individual Mermber of Parliament. Parliamentary. Parliamentary Groups. Legislative function.

Palabras clave: Parlamentario individual. Parlamento. Grupos. Función legislativa.

FECHA DE RECEPCIÓN: 15.07.2010 FECHA DE ACEPTACIÓN: 29.07.2011

107 F. RUBIO LLORENTE, «El Parlamento y la representación política», cit., pág. 157. Rubio tampoco ve inconveniente en que los parlamentarios actúen disciplinadamente y acepten la disciplina de voto, siempre que no se intente forzar esa disciplina creando instrumentos jurídicos que la impongan al parlamentario contra su propia voluntad, lo que sería ilegítimo (pág. 164).

108 I. ASTARLOA HUARTE-MENDICOA ( Perspectivas de modificación del procedimiento legislativo», El procedimiento legislativo. V Jornadas de Derecho Parlamentario, Congreso de los Diputados, Madrid, 1997, pág. 420) habla de «buscar con imaginación nuevos equilibrios».

109 Teniendo, según P. BIGLINO CAMPOS («Veinticinco años de procedimiento legislativo», cit., pág. 455), valor instrumental en relación con dicha finalidad las demás consideraciones, entre las que estarían procurar la agilidad del procedimiento, evitar el obstruccionismo, salvaguardar la disciplina interna de los partidos o garantizar la libertad de sus miembros. 